Review

\title{
The Search for Durable Exterior Clear Coatings for Wood
}

\author{
Philip D. Evans ${ }^{1,2, *}$, Jonathan G. Haase ${ }^{1}$, A. Shakri, B.M. Seman ${ }^{3}$ and Makoto Kiguchi ${ }^{4}$
}

1 Faculty of Forestry, University of British Columbia, 2424 Main Mall, Vancouver, BC V6T 1Z4, Canada; E-Mail: jo_haase@yahoo.com

2 Department of Applied Mathematics, Research School of Physics and Engineering, Oliphant Building 60, Mills Road, The Australian National University, Canberra, ACT 2601, Australia

3 Department of Building, Construction Engineering, Faculty Environmental \& Civil Engineering, Tun Hussein Onn University of Malaysia, Parit Raja, Batu Pahat, Johor 86400, Malaysia; E-Mail: shakri@uthm.edu.my

4 Forestry \& Forest Products Research Institute, Tsukuba 305-8687, Japan;

E-Mail: mkiguchi@ffpri.affrc.go.jp

* Author to whom correspondence should be addressed; E-Mail: phil.evans@ubc.ca;

Tel.: +1-604-822-0517; Fax: +1-604-822-9159.

Academic Editor: Mojgan Nejad

Received: 15 September 2015 / Accepted: 6 November 2015 / Published: 12 November 2015

\begin{abstract}
The goal of a durable exterior clear coating has eluded generations of coatings technologists, despite long-standing desire amongst the public for such a coating. The journey towards this goal initially focused on modifications to coating formulation, but took a completely different direction when it was found that a UV-transparent silicone clear coating on wood modified with chromic acid met consumer expectations of coating durability. This finding sparked world-wide interest in wood pre-treatments as a way of enhancing the durability of clear coatings. This interest initially focused on transition metal compounds, but has now shifted in the direction of organic and inorganic photostabilizers or even more drastic pre-treatments. Pre-treatments that dimensionally stabilize wood, protect it from microbial degradation and photostabilize lignin, when combined with flexible, photostable, coatings provide the next way-stop on the journey towards achieving the goal of durable exterior clear coatings for wood. This paper reviews this journey, drawing upon our research and that of other groups who have focused on this elusive goal.
\end{abstract}


Keywords: clear coating; varnish; durability; photostabilizers; wood modification

\section{Introduction}

There is long-standing desire amongst consumers for an exterior clear coating that will maintain wood's attractive natural appearance and protect it from environmental degradation. However, the performance of clear coatings on wood has generally been so poor that they are not recommended for the finishing of exterior woodwork unless regular and costly maintenance is carried out [1]. The performance of clear coatings on wood can be improved significantly by modifications to the coating or the underlying wood substrate, but such improvements have not yet led to the development of commercially available clear coatings that meet market expectations of coating longevity and performance.

In this paper we review research that has tested the longevity of clear coatings on wood and describe the reasons why they quickly fail outdoors. We then examine ways of improving their performance, looking first at modifications to the coating, and then examining how modification of the wood substrate and the wood-coating interface can improve coating performance. We then focus on the few studies that have attempted to improve clear coating performance by altering and optimizing the coating, wood-coating interface and also the underlying wood substrate. This holistic, "systems approach", has produced remarkable increases in the longevity of some clear coatings and appears to be the most feasible route towards achieving the goal of much more durable exterior clear coatings for wood.

\section{Longevity of Clear Coatings on Wood}

The longevity of clear coatings on wood was a subject of great interest to timber trade associations in the 1950s and 1960s. Their interest was stimulated by the public's interest in finishing exterior woodwork with clear coatings and the need to recommend the best product for this purpose. As a result, organizations such as the California Redwood Association and the Western Pine Association in the USA established comprehensive field trials to test the durability of clear coatings on wood. The National Research Council (NRC) of Canada did likewise. They were all disappointed by the results of their tests. For example, the Western Pine Association found that $90 \%$ of the clear coatings they tested failed to give satisfactory performance after 8 months of exterior exposure and the remaining $10 \%$ had a maximum life of 18 months [2]. Similarly, the California Redwood Association initiated a large scale testing program of clear coatings in the 1950s [3]. They tested close to 200 different clear finishes, of which only a handful were listed by them as possible candidates for the finishing of redwood (Figure 1a). These listed finishes failed within 20 months of outdoor exposure, and the poorer systems failed within six to nine months (Figure 1b) Because of these disappointing findings, the California Redwood Association stopped listing or recommending the use of clear finishes for redwood used outdoors. 

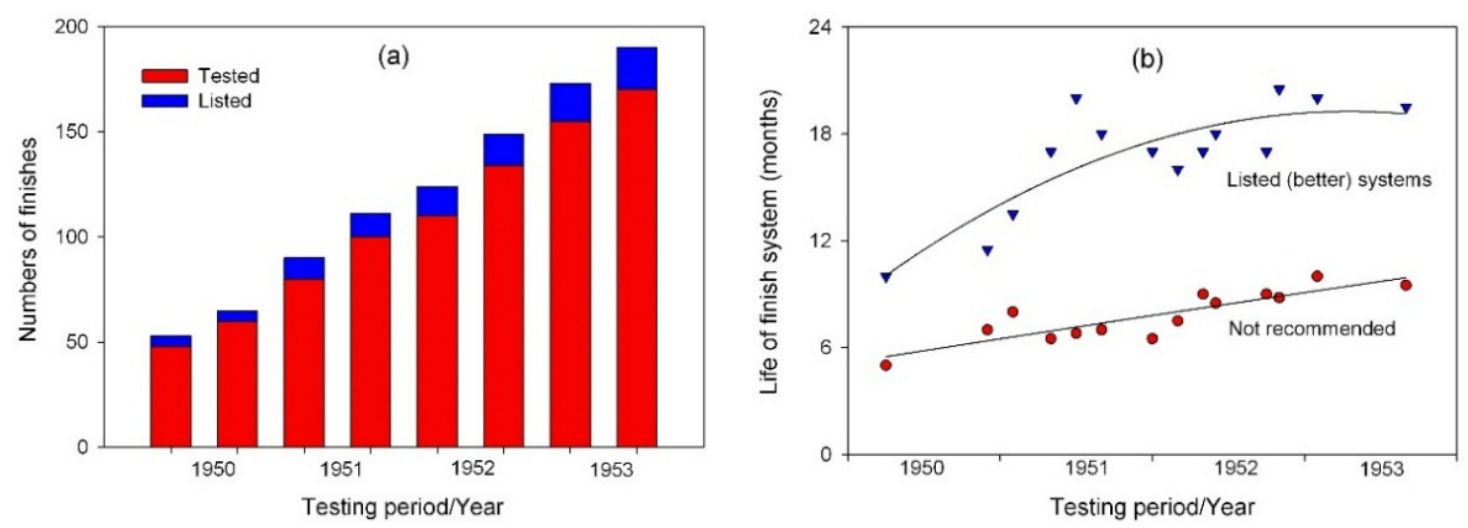

Figure 1. Summary of the results of the California Redwood Association's testing of clear finishes on wood exposed outdoors (re-drawn using data from Estrada [3]): (a) Numbers of finishes tested versus those listed as being suitable for the finishing of redwood; (b) Average life-times of the better listed finishes versus the poorer systems.

Testing of clear coatings in Europe a decade later produced similar results. Fessel reported that only $20 \%$ of the clear coatings on the market were effective, which he defined as coatings with a life-time of 30 months or more [4]. A similar figure was published a year later by Ashton [5] at the NRC in Canada. Initially he tested 28 different clear coatings (phenolic varnishes, alkyds and epoxy esters) and found that only six of them (21.4\%) were in good condition after 27 months of outdoor exposure, which he defined as "an absence of defects that detract from the appearance of the finished wood and would not interfere with recoating" [5]. In subsequent research, Ashton tested 42 clear coatings including 24 phenolic varnishes, 10 alkyds, four polyurethanes, three epoxies and one rosin-maleic cellulose acetate-butyrate coating [5]. Only eight of the coatings were in good or very good condition after two years outdoor exposure, and of these coatings seven were phenolic varnishes: the other was a polyurethane, which was ranked eighth [5]. Testing of 17 different surface finishes in Chile including two clear coatings (an alkyd and an "oil-based varnish") on samples of olivillo (Aextoxicon punctatum) and radiata pine revealed that the clear varnishes failed quickly and had lower weather resistance than pigmented stains and opaque film-forming finishes [6]. Dickinson exposed Scots pine and western red cedar panels finished with phenolic, alkyd or polyurethane varnishes to the weather in Sussex, UK, and found that "after 18 months of exposure the timber surface was so badly affected that restoration would have been extremely difficult" [7]. Similarly, Borgin and Corbett observed that a clear alkyd varnish on radiata pine had completely failed after 2 years exposure in South Africa [8]. A photograph in their paper of one of the failed panels shows extensive peeling of the varnish from the underlying wood, cracking of the varnish and its colonization by mould fungi [8]. The appearance of the coating is so poor that it is quite likely that "failure" occurred well before the end of the two-year trial [8]. Macedo observed that a polyurethane clear coating ( 3 coats) on untreated Paraná pine wood was in "fair" condition (60\% to 70\% of surface damaged) after 12 months exposure in São Paulo, Brazil [9]. However, in the following 6 months the condition of the panels deteriorated further and they were rated as being in poor condition ( $80 \%$ to $100 \%$ of surface damaged) [9]. Another Brazilian study found that a clear polyurethane varnish failed on pine and eucalyptus window joints after only 10 months of outdoor exposure [10]. Williams and Feist tested the performance of a clear polyurethane varnish and a clear silicone coating on untreated and pre-treated western red cedar and Douglas fir wood [11]. The polyurethane varnish (one or two coats) 
failed within two years on both wood species. The clear silicone coating performed better and was in good condition except on the western red cedar panels that were finished with only one coat of varnish [11]. More recent field testing has confirmed the disappointing results of earlier trials. For example, Kiguchi and co-workers found that silicone-urethane and polybutadiene varnishes on sugi failed within 6 months of exterior exposure in Tsukuba, Japan [12]. A fluorine clear coating failed within a year of outdoor exposure [13]. Morris and co-workers tested the performance of four clear coatings as part of a trial to evaluate the field performance of natural finishes applied to Douglas fir [14]. All but one of the finishes failed after 12 months exposure in Vancouver or Mississippi, and the one finish that was better than the others failed after 18 and 24 months exposure in Mississippi and Vancouver, respectively [14]. In subsequent research, Morris and McFarling found that a slightly pigmented water-based polyurethane finish and a water-based clear acrylic varnish on vertical grain Douglas fir heartwood failed after 15 and 20 months exposure in Mississippi, respectively [15]. Petrič and co-workers exposed Scots pine sapwood panels finished with acrylic or alkyd clear coatings to 12 months of natural weathering at two sites in Slovenia (Ljubljana and Rateče) [16]. Photographs of weathered panels in their paper show that the acrylic coating failed at both sites after 12 months exposure [16]. The alkyd coating suffered a similar fate at the Ljubljana site, but was performing slightly better at Rateče after 12 months exposure [16]. Schaller and Rogez observed that an unpigmented long-oil alkyd on radiata pine was starting to fail by delamination and cracking after 12 months exposure in Switzerland and had completely failed after 18 months exposure [17]. More recently, Stirling and Morris found that a urethane-acrylic finish failed on pine and spruce after 7 and 14 months exposure in Mississippi and Vancouver, respectively [18]. Pandey and Srinivas found that a polyurethane clear coating ( 2 coats) on untreated rubberwood failed after only 6 months exposure in Bangalore, India [19]. Grüll and co-workers found that a thick acrylic clear coating on Scots pine sapwood failed after 28 months exposure in Vienna, Austria [20].

In summary, numerous studies have confirmed the poor performance of clear coatings on wood exposed outdoors. Most clear coatings fail within two years of outdoor exposure in temperate climates and failure within a year frequently occurs in tropical climates. Failure of clear coatings has generally been defined as inability of the finished wood to be re-coated without excessive stripping of the coating or, alternatively, unacceptable appearance of the finished wood to the consumer. When the latter "failure" criterion is used shorter lifetimes are produced. We examine why the performance of exterior clear coatings is so poor in the following section.

\section{Mechanisms for the Failure of Clear Coatings on Wood}

There is no single mechanism responsible for the rapid failure of clear coatings on wood, but the transparency of the coatings to UV and visible light makes them much more susceptible than opaque coatings to delamination caused by photodegradation of wood beneath the coating. However, other mechanisms are involved in the failure of clear coatings on wood, depending on the type of polymer binder in the coating and the extent to which the coating is exposed to the different agencies that degrade coatings (principally UV and visible light, water and micro-organisms).

Clear coatings containing binders that are susceptible to photodegradation and hydrolysis can fail due to degradation of the coating, in addition to degradation of the underlying wood. Such degradation of the coating includes discolouration (yellowing), loss of gloss, and changes in the mechanical and 
physical properties of the coating film. Loss of coating flexibility was noted very early on as a key indicator of the degradation of clear coatings on wood [21]. Clear coatings that are susceptible to degradation include those containing epoxy, urethane, polyamide, alkyd or phenolic resins. For example, Ashton noted that epoxy clear coats failed because the film itself was degraded resulting in flaking of the coating [5]. He also noted that "polyamide-epoxies performed badly, possibly because polyamides are susceptible to UV degradation" [5]. In accord with Ashton's findings, Estrada noted that epoxy and polyamide systems failed by losing gloss and cracking, in addition to delamination [3]. Miniutti noted that phenolic and polyurethane varnishes were degraded and their thickness reduced by exposure to long-wave UV radiation [22]. Coating failure also occurs with alkyd varnishes [23]. Alkyd films and other coatings can also be physically and chemically degraded by Aureobasidium pullulans, the staining fungus that commonly colonizes the surface of clear coatings exposed outdoors [24]. This fungus is also able to grow on, and penetrate alkyd varnish and also acrylic paint films [7,9,25].

Degradation of wood beneath clear coatings exposed to weathering or UV radiation has been examined in numerous studies [22,26-29]. Miniutti observed that diagonal pit micro-checks and erosion of the middle lamella, the intercellular layer in wood that bonds fibres (tracheids) together, occurred in wood beneath clear coatings exposed to the weather or UV radiation [26]. Similar changes occur at wood surfaces that are directly exposed to natural or artificial accelerated weathering (Figure 2). Miniutti [26] suggested that pit micro-checking and erosion of middle lamellae might create strains sufficiently large enough to cause cracking of overlying clear coatings. He noted that pit micro-checking was more pronounced in low density springwood (earlywood) than higher density summerwood (latewood) and suggested that this might explain why clear coatings failed more rapidly on springwood than summerwood: the opposite of the pattern of failure of opaque paint films on wood. Macleod and co-workers observed that an acrylic coating on western red cedar offered some protection to wood from photodegradation, although ultimately loss of lignin from the coated wood surface was similar to that observed for uncoated wood [27].

Lignin is concentrated in the middle lamella that bonds wood cells together, and degradation of this layer in tracheids at the wood coating interface was responsible for the delamination of acrylic, polyester and polyurethane clear coatings on radiata pine sapwood exposed to the weather for 6 months in New Zealand [29]. Microbial colonization of photodegraded cells beneath the clear coating was observed, but there was no evidence of microbial degradation of wood cell walls [29]. However, in the tropical climate of Malaysia, Shakri observed that poor adhesion of a clear coating to kempas (Koompassia malaccensis) wood exposed to the weather for 18 months was associated with increased microbial colonization at the wood-coating interface (Figure 3), as well as photodegradation of the wood itself [28]. Blue stain fungi "festering under a coat of varnish can lead to considerable damage to the varnish film", according to Uiterwaal and Blom [30]. For example, fungi growing under the coating can produce fruiting structures (pustules) that erupt through the film destroying its integrity $[31,32]$. This mode of growth is probably the most destructive of a varnish film, according to Dickinson [7]. 

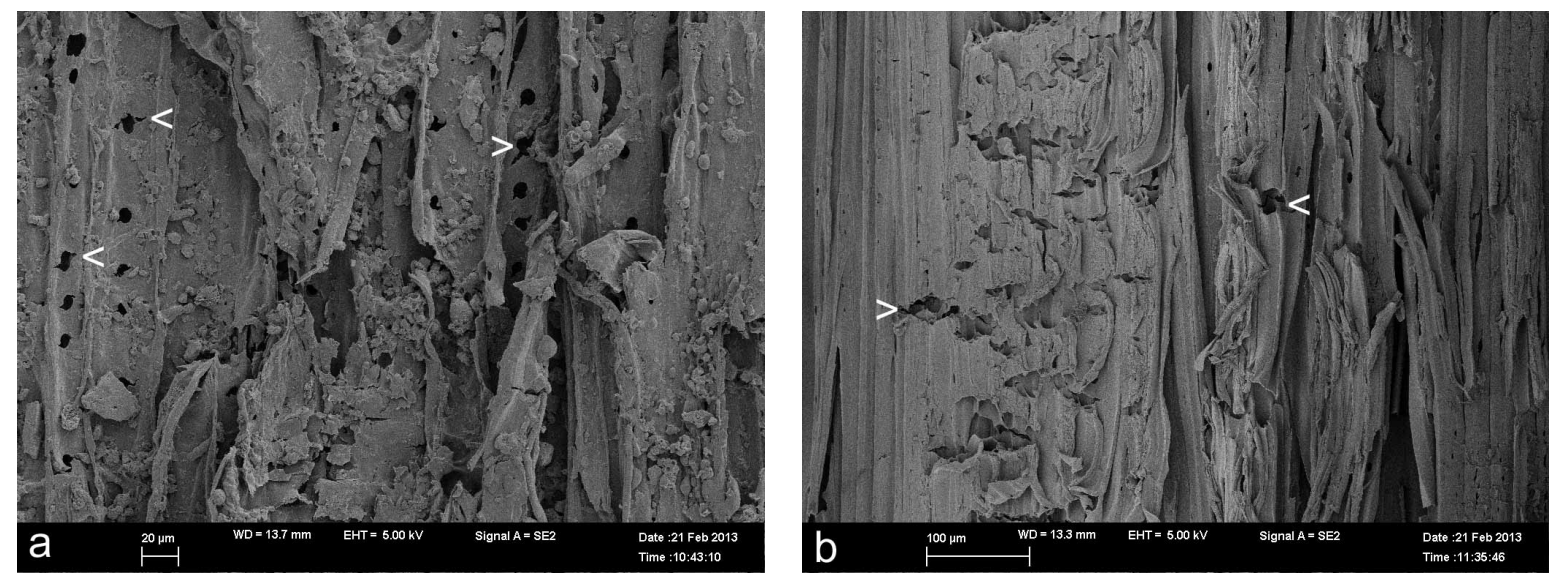

Figure 2. Formation of pit micro-checks and longitudinal separation of tracheids at wood surfaces exposed to weathering: (a) Pit micro-checking (arrowed left and right of centre) at the surface of western hemlock wood exposed to natural weathering for 62 weeks. Note the colonization of the surface by staining fungi; (b) Deep pit micro-checking (arrowed left and right of centre) at the surface of western hemlock wood exposed to artificial accelerated weathering for $4000 \mathrm{~h}$. There is also separation of tracheids from the underlying wood due to degradation of middle lamellae.
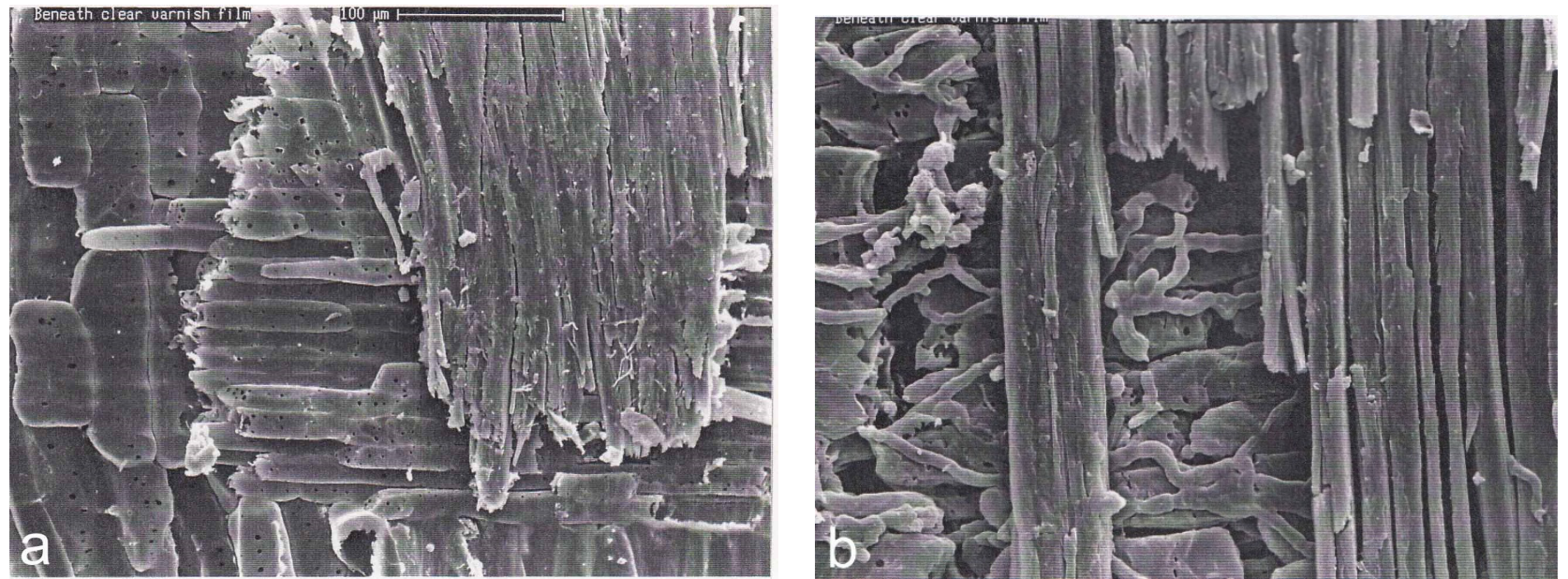

Figure 3. Surface of kempas wood beneath a clear coating exposed outdoors for 18 months: (a) Area beneath part of the coating that adhered well to the wood; (b) Area beneath part of the coating that adhered poorly to the wood. Note the colonization of the wood surface by staining fungi.

An even more destructive agency is hail. Hail can indent and crack clear coatings leading to moisture ingress through the coating and colonization of the underlying wood by staining fungi. Uiterwaal and Blom show aliform fungal staining of a clear coating around indentation marks caused by hail [30]. They also show how such damage can be prevented by covering weathering racks with fine wire netting [30].

The degradation of wood beneath coating films occurs at the same time as degradation of the coating [23]. Both contribute to failure of clear coatings although wood degradation and delamination or peeling predominate for coatings based on UV transparent binders (acrylic and silicone systems) or coatings whose photostability has been increased through the use of additives (Figure 4). In general the 
first sign of failure of clear coatings on wood is light coloured spots or streaks, which are associated with small perforations or micro-cracks in the coating. Lightening of clear coatings on wood can also develop in the absence of such cracks. For example, Browne wrote that varnish develops milky opaque patches where the coating has lost adhesion without breaking open [33]. He also added that other varnishes craze or crack in an unsightly manner [33]. Cracks often occur in areas where the coating is thin and/or where there is micro-checking of the underlying wood [26]. Loss of coating elasticity presumably makes the coating more susceptible to cracking. Cracks in the coating provide pathways for moisture, which encourages colonization of the wood coating interface by staining fungi. These fungi create dark streaks or lens-shaped areas on the coated wood, which grow in size. Coating films peel away from these areas because of poor adhesion between the coating and the wood. Peeling was noted as an important symptom of failure of a clear polyurethane coating applied to pine and eucalypt window joints that were exposed to the weather for 10 months in Brazil [10]. If a coating is brittle it may flake rather than peel away from the wood. The development of numerous cracks in the coating followed by moisture ingress and microbial colonization quickly leads to the complete failure of the coating. This form of failure is quite common although other forms of failure occur. For example, very hard inflexible coatings fail even more quickly by cracking and large-scale delamination of the coating [34]. Clear coated wood products in tropical climates can fail very quickly due to decay of the wood before there is complete failure of the clear coating [10].
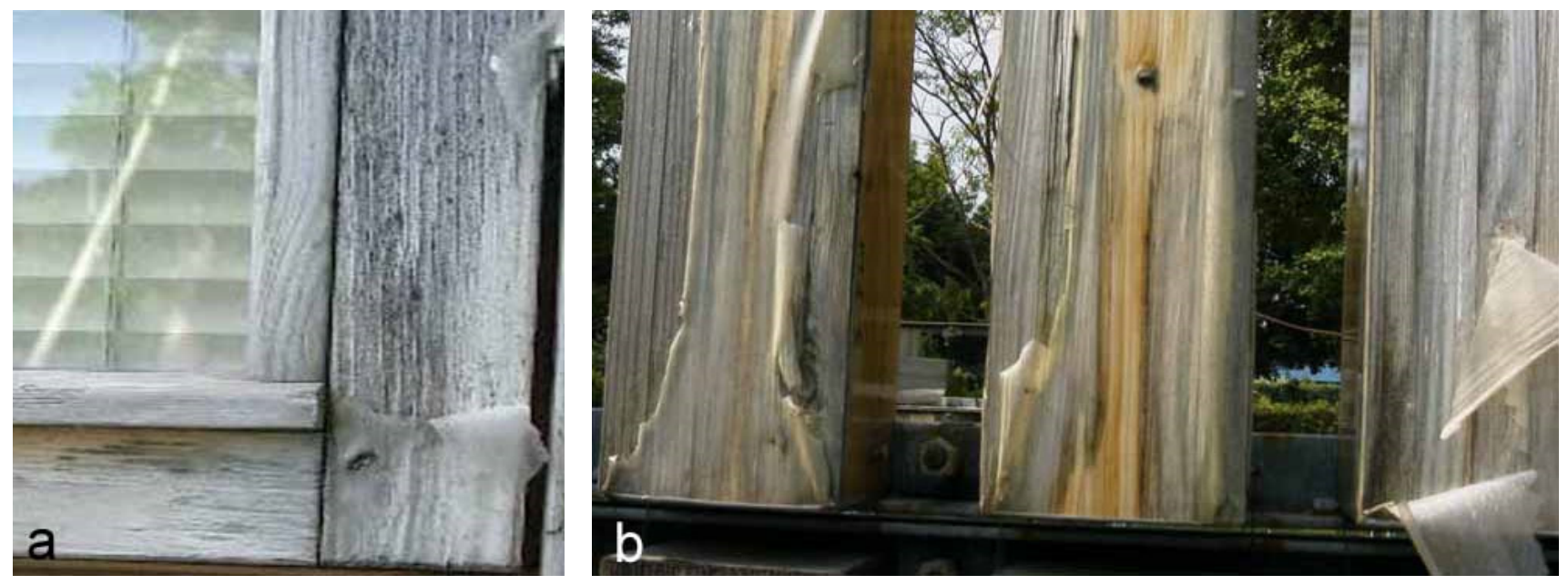

Figure 4. Peeling and delamination of clear coatings on wood due to photodegradation of wood beneath the coating: (a) Clear coating peeling from a vertical window casing in a private house in southern France. Note the fungal staining of wood beneath the clear coating; (b) Fluorine resin-based clear coating peeling from glulam test specimens exposed to the weather in Japan.

An understanding of the mechanisms of failure of clear coatings explains why attempts to improve the performance of clear coatings on wood have focused on increasing the resistance of the coating and the underlying wood substrate to environmental and microbial degradation. Both will be examined in the following two sections. 


\section{Modification of Coatings to Improve Clear-Coat Performance}

Modification of coating and film properties was the focus of much of the early research on improving the performance of clear coatings and it continues to be an area that attracts interest.

\subsection{Coating Thickness and Uniformity}

The effects of film thickness on the durability of clear coatings was examined as early as 1937 by Schuh and Theuerer [35]. They found that the durability of clear coatings on a metal substrate depended on film thickness and coating type. For example, long-oil varnishes performed better when thick films were used whereas the same could not be said of short-oil varnishes. A positive effect of coating thickness (1 versus 2 coats) on the performance of a polyurethane varnish on Douglas fir plywood exposed outdoors for 30 months was noted by Williams and Feist, although they found no effect of coating thickness on the performance of the varnish on western red cedar [11]. Similarly, Black and Mraz found little effect of coating thickness in the range of 51-152 $\mu \mathrm{m}$ on the outdoor durability of a silicone clear coating on ponderosa pine, redwood or western red cedar [36]. Miniutti emphasized the need to have a minimum thickness of a clear coating to cover vertically projecting springwood cell walls, which raised stresses and increased checking in the clear coating [22]. The need to create a uniform coating that evenly covers the finished wood surface was also emphasized by van Loon [37]. He noted that clear coating films can be very thin over the pores of ring porous hardwoods [37]. On these thinly covered areas the coating quickly fails by cracking, blistering and peeling [37]. Clear coatings can fail due to the action of staining fungi, as noted above, and thicker coatings may be better at resisting hyphal penetration by such fungi. For example, Sharpe and Dickinson observed that a thick clear alkyd coating was less easily penetrated by blue stain fungi than some thinner opaque finishes [25]. Despite these positive effects of coating thickness on the performance of clear coatings, Cassens and Feist wrote that "regardless of the number of coats applied, the clear finish will eventually become brittle as a result of exposure to sunlight, develop severe cracks and peel, often in less than 2 years" [38]. Browne mentioned the need to apply at least three coats of varnish to new wood and one coat when the coating needed to be renewed, but he added that after two or three renewals the coating will be too thick, and it will begin to crack and scale badly [33].

\subsection{Coating Flexibility}

Cracking of clear coatings is an indication they lack sufficient flexibility to accommodate the surface strains that develop when wood swells and shrinks. These strains are not uniform at wood surfaces and are concentrated in areas where the coating may also be thin, for example over resin canals or vessels, as noted above. If a coating lacks sufficient flexibility to accommodate such strains, and its adhesion to the underlying wood substrate is good, then a crack will develop. For this reason coating flexibility has been the focus of much research aimed at improving the performance of clear coatings on wood. Hunt and Lansing referred to flexibility as distensibility and found that loss of distensibility when a clear coating ages outdoors could be used to predict the durability of the coating [21]. Coating flexibility has been assessed using the susceptibility of the resin to crack when bent over a narrow rod, or by measuring its tensile properties [39]. More recently the glass transition temperature $\left(T_{\mathrm{g}}\right)$ has been used as an 
indicator of coating flexibility. $T_{\mathrm{g}}$ is the temperature at which an amorphous solid becomes soft upon heating or brittle upon cooling. Coatings with high $T_{\mathrm{g}}$ values are brittle, and hence wood coatings for use outdoors should possess and maintain relatively low $T_{\mathrm{g}}$ values [40,41]. Clear and semi-transparent coatings formulated from resins with a high $T_{\mathrm{g}}$ fail before ones formulated from a resin with a low $T_{\mathrm{g}}$. For example, Schmid applied two semi-transparent stains with glass transition temperatures of 10 and $50{ }^{\circ} \mathrm{C}$ to wood, and exposed the treated panels to the weather [40]. The cracking of the coating containing the binder with the high $T_{\mathrm{g}}$ began after 1 year of exposure while no cracking was observed in the finish containing the binder with a $T_{\mathrm{g}}$ of $10{ }^{\circ} \mathrm{C}$ [40]. Vollmer and Evans also observed that a hard inflexible acrylic coating formulated for metals failed far more quickly on wood than more flexible coatings [34]. The relationship between the flexibility of phenolic varnishes and alkyd clear coatings and their durability on wood exposed to the weather was examined by Ashton [39]. He found that the alkyd clear coats retained their flexibility much longer than the phenolics, but the phenolic vanishes performed better than the alkyds [39]. The superior performance of the phenolic varnishes appeared to be related to their low water absorption and water vapour permeability [42]. Hence, Ashton concluded that "flexibility, therefore, is not so important as water absorption, water vapour permeation, or transparency to UV light in relation to the performance of clear finishes, even on such a dimensionally unstable substrate as wood" [39].

\subsection{Coating Composition and Binder Type}

The type of binder used in clear coatings has a large influence on the durability and performance of clear coatings and this is apparent from the sections above on coating longevity and failure mechanisms of clear coatings used outdoors. Some coatings are unsuitable because they are not sufficiently photostable, for example, the epoxy and polyamide-epoxy clear coats tested by Ashton [5]. Others are unsuitable because they are not water resistant, for example shellac, or do not adhere strongly to wood or are discoloured by exposure to water and light (cellulose acetate and cellulose acetate butyrate clear coatings for example), [5,21]. Coatings are usually formulated from mixtures of different materials and, within the broad classifications of coatings denoted by binder type (phenolic, alkyd, acrylic, etc.), considerable variation in coating composition occurs. Coating composition is varied to increase the flexibility of clear coatings, which is an important attribute affecting the durability of clear coatings on wood, as noted above. The flexibility and durability of phenolic and alkyd varnishes is affected by their oil content and type, and these topics were examined by Ashton and co-workers in a series of papers $[5,42,43]$. They found that tung oil phenolic varnishes were generally more durable than linseed oil varnishes and both were better than dehydrated castor and soya varnishes. In contrast, soya alkyds were more durable than linseed alkyds. The durability of tung and linseed $p$-phenyl propane varnishes reached a maximum at oil contents of $58 \%$ to $66 \%$ by weight. There was no clear relationship between the oil content and durability of alkyd varnishes.

The inherent durability of silicone and fluorine-based clear coatings is good and they perform well on some substrates. Their good performance is partly due to their high UV resistance and, in the case of coatings containing fluorinated polymers, to the high bond energy of the $\mathrm{C}-\mathrm{F}$ bond $(490 \mathrm{~kJ} / \mathrm{mol}$ compared to $340 \mathrm{~kJ} / \mathrm{mol}$ for the $\mathrm{C}-\mathrm{C}$ bond). Both silicone and fluorine-based clear coatings have performed very well on wood when combined with a UV protective chromium pre-treatment $[36,44]$. 
The performance of silicone clear coatings on unmodified wood varied with wood species, performing very well on poplar and failing badly on southern pine [36]. The performance of fluorine-based clear coatings in the limited testing that has been conducted on unmodified wood has generally been poor. For example, Kiguchi found that a fluorine clear coating failed within a year of outdoor exposure in Japan [13], as mentioned above. Morris and co-workers found that a Teflon-containing semi-transparent stain failed on untreated Douglas fir after only 6 months exposure in either Vancouver or Mississippi [14].

\section{Use of Additives to Improve Clear-Coat Performance}

Photoprotective additives including UV absorbers (UVA), hindered amine light stabilizers (HALS) and transparent inorganic particles, and also fungicides are commonly added to clear coatings to improve their outdoor performance.

\subsection{UV Absorbers}

UV absorbers were introduced commercially in the 1940s (Figure 5), and one of their earliest uses was to improve the performance of clear coatings [45]. For example, early research in the 1940s found that adding UV absorbers to clear nitrocellulose lacquers was effective at preventing the darkening of natural and bleached furniture woods [46].

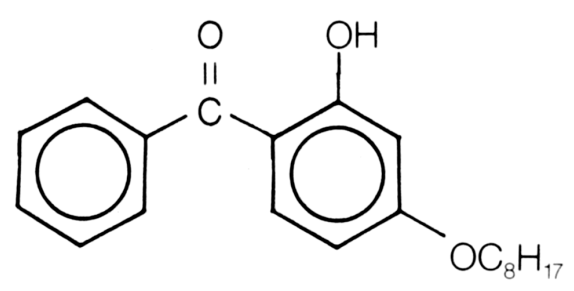

(a)

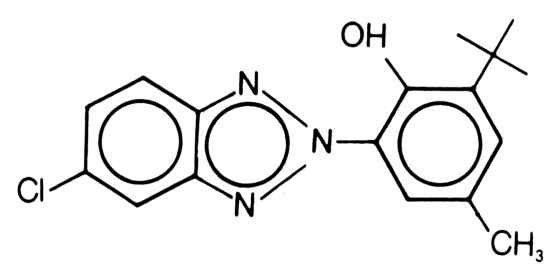

(b)

Figure 5. Chemical structures of typical (a) benzophenone and (b) benzotriazole UV absorbers used to photostabilize clear coatings and wood.

Subsequent research showed that substituted benzophenones, particularly 2,4-dihydroxy-benzophenone were highly effective UV absorbers [47]. However, mixed outcomes were reported in early work on the use of UVAs to improve clear coating performance on wood. Estrada found that the addition of $0.5 \%$ and $1.25 \%$ of a benzophenone UVA improved the performance of solvent and water-based clear coatings, respectively, on redwood, western red cedar and white pine [48,49]. In follow-up work, Estrada tested the effects of different concentrations of a benzophenone UV absorber $(3.8 \%, 4 \%$ and $10 \%)$ on the outdoor performance of epoxy-clear coats on edge-grain redwood [3]. He also tested the effects of adding a benzotriazole UV absorber (5.3\%) on the performance of a polyester clear coating [3]. The best performing epoxy clear coatings were the ones that contained the UV absorber, particularly the formulation containing 10\% UVA [3]. Conversely, the addition of the benzotriazole UV absorber to the polyester did not improve its performance [3]. Ashton, Harris and co-workers reported that a UVA at $0.5 \%$ concentration was ineffective at "slowing exterior degradation of an alkyd, an oil-modified urethane and a phenolic varnish" on western red cedar panels [3,43]. However, they acknowledged that $4 \%$ of UVA and in some cases up to $10 \%$ might be needed for many materials [43]. 
The results of Estrada and Ashton and co-workers highlights the lack of information in the 1950s and 1960s on the type and concentrations of UV absorber needed to improve the performance of exterior clear coatings $[3,5,43,48,49]$. This was an issue that concerned Kiefer who stated that "very little unbiased data are to be found on the effectiveness and side effects of the (UV) absorbers in clear coatings for wood" [45]. He went on to test the effects of 11 different UV absorbers at different concentrations ( $1 \%$ to $8 \%$ ) on the outdoor performance of a tung oil phenolic, an oil-modified polyurethane and an alkyd resin varnish on maple. He also attempted to correlate the results of outdoor exposure with the ability of the UV absorbers to block the transmission of light through the different coatings. He found that benzophenone UV absorbers at $2 \%$ to $8 \%$ concentration were the most effective ones at restricting loss of gloss of coated panels exposed to the weather in Florida for two years [45]. However, only one benzophenone UVA was effective at restricting loss of gloss of the oil-modified polyurethane [45]. A benzotriazole UV absorber was also tested by Kiefer, but it did not perform as well as some of the benzophenones, and it gave erratic effects on the gloss of the alkyd clear coating [45]. Substituted acrylonitrile UVAs did not perform well in Kiefer's tests [45]. Furthermore, he found that UV absorbers that were good at blocking transmission of UV radiation through clear coatings could not be assumed to be the best at improving the performance of the coatings on wood [45]. He concluded that UVA's considered for use in a clear coating must be evaluated in that particular finish to determine whether or not they are effective at prolonging the life of the coating [45]. Around the same time that Kiefer was carrying out his comprehensive tests [45], Rothstein tested the ability of different UV absorbers (3\%) to prevent the light-induced yellowing of tung-oil phenolic, alkyd and polyurethane clear coats [50]. Clear coatings were applied to white Formica rather than solid wood and exposed to the weather in Florida or Arizona. A hydroxyl-phenyl benzotriazole was the most effective UVA at restricting the yellowing of the clear coatings whereas a substituted acrylonitrile was the least effective [50]. Ashton examined the effect of a benzophenone UVA (2,2'-dihydroxy-4-methoxy-benzophenone) at different concentrations on the performance of various clear coating systems on western red cedar panels exposed to the weather in Ottawa for 4 years [51]. The UVA at a high concentration of $7.5 \%$ slightly increased the durability of a phenolic varnish, but his most notable finding was that a phenolic alkyd clear coating containing 5\% UVA only exhibited slight change after 4 years exposure [51]. In contrast there were severe changes (failure) to the control after 4 years exposure [51]. Since these pioneering studies there has been much additional research by coatings and chemical companies to develop new more effective UV absorbers, some of which are better than benzophenones at improving the performance of clear coatings.

More recent research has tested different benzotriazole UV absorbers in clear coatings and has found that they are effective at preventing the photo-induced discolouration of urethane-modified acrylate and polyurethane clear coatings [52,53] and a polyester clear coating [54]. Furthermore, studies by Chang, Chou and co-workers demonstrated that addition of a benzotriazole UVA to clear coats can also decrease the discolouration of the underlying wood as well as that of the clear coat $[52,53,55]$. The same benzotriazole UVA used in these studies was also effective at inhibiting the cracking of a clear coating on grand fir and European oak panels exposed to accelerated weathering [56]. This positive effect was thought to be due to the ability of the UVA to modify the elasticity of the coating $\left(T_{\mathrm{g}}\right)$ and prevent it from becoming brittle when exposed to UV light and water [56]. UV absorbers are generally added at a level of $1 \%$ to $5 \%$ to stabilize clear coatings on wood used outdoors or a lower amount can be used if they are combined with a hindered amine light stabilizer (HALS) [57]. However, increasing the 
concentration of UV absorber in clear coatings beyond the normal levels can have positive effects on coating performance. For example, the addition of twice the "normal" level of UV absorber to a 2-part polyurethane clear coating had a positive effect on the fungal discolouration of coated Douglas fir and ponderosa pine panels exposed to the weather in Vancouver or Mississippi, according to Morris and co-workers [14].

An alternative to increasing the concentration of UV absorber in clear coatings is to select ones that are better at screening the components of the UV and visible spectrum that cause degradation of clear coatings. This was the approach taken by Hayoz and co-workers [57]. They describe the development of a triazine UV absorber that was more effective at restricting the light-induced colour changes of clear coated wood because the UV absorber was more photostable than benzophenone and benzotriazole UV absorbers and its absorption maximum was (red)-shifted towards the visible part of the spectrum. Most studies show that UV absorbers have a positive effect on the performance of clear coatings, but clear coatings can fail on wood due to the effects of water and fungi, in addition to solar radiation. Therefore, it is not surprising that some studies have found that UV absorbers have little effect on the performance of clear coatings on wood exposed to the weather. For example, Shakri found that a benzotriazole UV absorber was ineffective at improving the performance of a varnish on kempas panels exposed to the weather in Malaysia for 18 months [28]. However, the combination of a benzotriazole UVA and a HALS was far more effective at improving the performance of the finish [28].

\subsection{Hindered Amine Light Stabilizers and Their Combination with UV Absorbers}

Hindered amine light stabilizers (HALS) are thermally and light-stable derivatives of 2,2,6,6-tetramethyl piperidine that are widely used to photostabilize polymers (Figure 6). They have been tested on their own to see if they can reduce the discolouration of clear coatings, but they mainly find practical application in combination with UV absorbers [17].

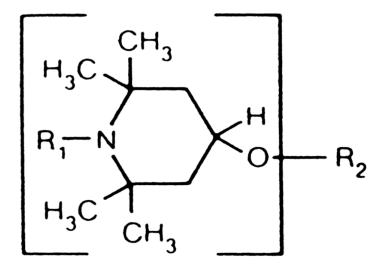

(a)

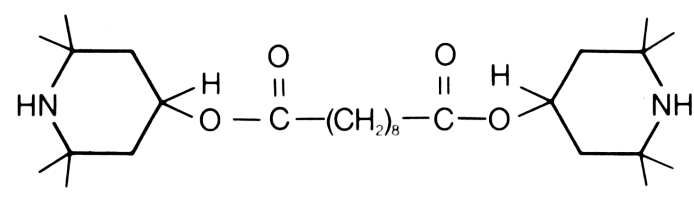

(b)

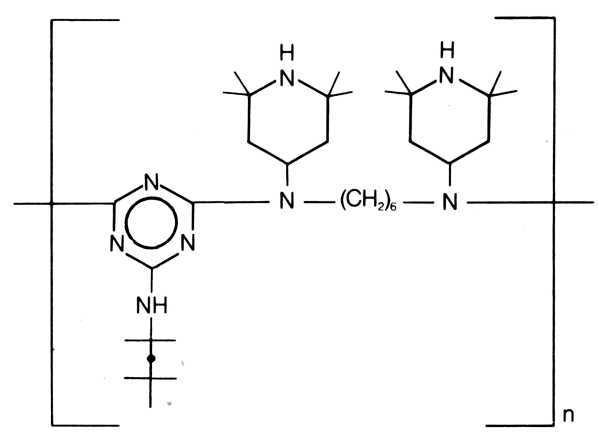

(c)

Figure 6. Generalized structures of hindered amine light stabilizers (HALS): (a) 2,2,6,6-tetramethyl piperidine; (b) Low molecular weight HALS; (c) Oligomeric HALS. 
Shenoy and Marathe tested the effects of two hindered amine stabilizers at four concentrations $(0.5 \%$, $1.0 \%, 2.0 \%$ and $2.5 \%$ ) on the yellowing and darkening of a polyester clear coating on aluminium panels exposed to accelerated weathering [54]. They did not observe a dose-response-effect of the HALS on the yellowing or darkening of the polyester, but the combination of the HALS with a UVA had a synergistic effect on reducing the discolouration of the coating [54]. Similarly, Chang and Chou found that a HALS "was not really helpful at inhibiting the photodiscolouration of a urethane modified acrylic coating", but they observed that the HALS had a significant synergistic effect in combination with a UVA at inhibiting the photodiscolouration of the clear coating on red oak [52]. This synergistic effect was due to the ability of the HALS to prevent photodegradation of the polymeric coating and also the UV absorber added to the coating [52]. Shakri observed that a HALS on its own reduced the darkening of clear-coated kempas panels, but the combination of a HALS and UVA had a synergistic effect on the discolouration and performance of the clear finish (Figure 7) [28].

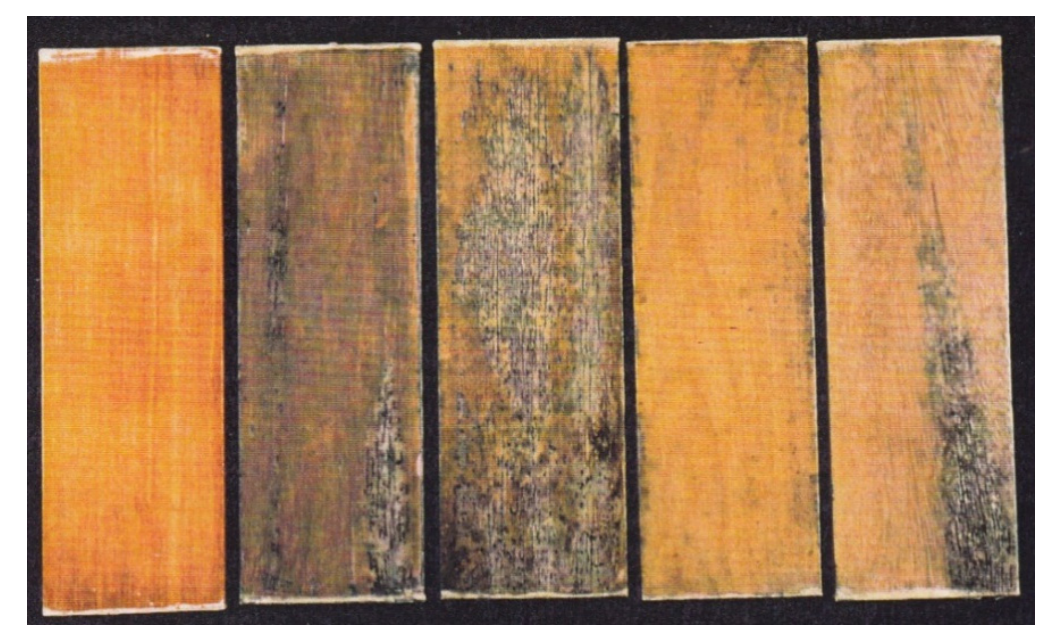

Figure 7. Effect of adding a UV absorber and hindered amine light stabilizer (HALS) to a clear coating on the performance of clear-coated kempas wood panels exposed to the weather for 18 months in Malaysia. From left to right: Unweathered control; weathered control; coating containing $2 \%$ benzotriazole UVA; coating containing $2 \%$ benzotriazole UVA and $2 \%$ HALS; coating containing $2 \%$ HALS.

Pereira and Eusébio observed that a HALS improved the performance of an acrylic clear coating on maritime pine exposed to artificial or natural weathering, but again the combination of a HALS and UVA was better at improving performance than either of the additives on their own [58]. More recently, Forsthuber and Grüll found that the combination of a HALS and UVA was better at restricting the photodegradation of an acrylic clear coating on Norway spruce than a UVA on its own [59]. In contrast to most previous findings Aloui and co-workers found that a combination of HALS and UVA was no better than a UVA at improving the appearance or degree of cracking of a clear coating on oak, and the combination only improved the appearance of the coating on grand fir [56].

\subsection{Inorganic Photostabilizers}

Inorganic particles are commonly used as pigments in opaque coating systems. The transparency of the particles can be increased by reducing their size and this has led to much recent interest in using 
metallic oxides with very small average particle size (nanoparticles) as photoprotective additives for clear coatings on wood. The use of nanoparticles to improve the performance of pigmented and transparent coatings on wood was recently reviewed by Nikolic and co-workers [60]. Their review focussed on the effects of nanoparticles on the UV absorption characteristics and physical properties of coatings. They concluded from the literature they reviewed that inorganic nanoparticles can be efficient UV absorbers in coatings depending on the type, loading, sizes and dispersion of the nanoparticles [60]. Nanoparticles can also have a positive effect on the ability of coatings to restrict moisture uptake by wood [61]. Both of these effects improve the durability of coatings on wood. However, as mentioned by Nikolic and co-workers almost all of the recent studies that have tested the durability of coatings containing nanoparticles have employed artificial weathering [60]. Hence, they point out that additional natural weathering trials are needed to fully test the effectiveness of inorganic nanoparticles at improving coating performance [60].

Recent interest in the use of inorganic nanoparticles in clear coatings was preceded by some early research by Estrada on the use of colloidal iron oxide as an additive to improve the performance of a urethane clear coat on edge grain redwood [3]. He found that the urethane coating containing colloidal iron oxide out-performed all other urethane coatings after 33 months outdoor exposure [3]. However, the coating darkened considerably during exposure, and this undesirable effect may have deterred others from looking at the use of inorganic particles as photostabilizers for clear coatings on wood [3]. Boxall and co-workers noted that inorganic particles reduced the transparency of clear coatings, but their research found that European beech panels finished with a urethane clear coating containing pulverized fuel ash "rated well after 6 years outdoor exposure in the UK" [62]. The combination of the urethane and the pulverized fuel ash produced a stronger, less extensible film, that failed initially by chalking and then "through the usual mechanism of cracking and delamination of the coating film" [62]. In contrast to these observations, Aloui and co-workers found that transparent cerium or titanium oxide particles were not very effective at improving the performance of a clear coating on oak and grand fir [56], although, in accord with Boxall and co-workers [62], they observed that the inorganic particles reduced the flexibility of the coating [56]. In subsequent research, Aloui and co-workers found that transparent titanium dioxide and iron oxide particles, particularly the latter, were less effective than a UVA or a UVA/HALS combination at restricting the discolouration and cracking of a clear coating on grand fir and oak panels exposed to accelerated weathering [63]. Allen and co-workers found that the rutile form of titanium dioxide nanoparticles was an effective stabilizer for clear coatings on pine wood, with performance greater than or equal to organic UV absorbers and HALS [64]. Particles $70 \mathrm{~nm}$ in size were more effective than $90 \mathrm{~nm}$ particles [64]. They observed no synergy between the particles and a HALS on coating performance [64]. Weichelt and co-workers found that spruce wood samples finished with clear coatings containing zinc oxide nanoparticles were less discoloured after accelerated weathering than samples finished with an unmodified coating [65]. The effectiveness of the modified coating at reducing discoloration was further enhanced if the wood was pre-treated with an organic "lignin stabilizer" [65]. Similarly, Cristea and Riedl showed that zinc oxide and titanium dioxide nanoparticles improved the durability of clear coatings on black spruce wood exposed to accelerated weathering [66]. Auclair and co-workers compared the ability of different inorganic (zinc or copper oxide nanoparticles) and organic photostabilizers (UVA/HALS) to prevent the discolouration of clear-coated sugar maple panels exposed to accelerated weathering [67]. The best photoprotection was obtained with zinc oxide 
nanoparticles $(2 \% \mathrm{w} / \mathrm{w})$ [67]. The combination of inorganic and organic UV absorbers was also effective and showed synergistic effects on the gloss of the coatings [67]. Schaller and co-workers also compared the ability of different organic and inorganic photostabilizers to prevent the deterioration of clear-coated pine panels exposed to accelerated weathering [68]. Their panels were pre-treated with a lignin stabilizer and the acrylic coating they tested also contained a HALS [68]. They found that a triazine UVA outperformed all other photostabilizers including the inorganic nanoparticles [68]. The best inorganic photostabilizer was titanium dioxide, which outperformed zinc oxide and cerium dioxide nanoparticles [68]. Ozgenc and co-workers compared the effects of micronized titanium dioxide and a triazine UVA in an acrylic clear coating on the discolouration of coated Scots pine and European beech exposed to accelerated weathering [69]. Both UV stabilizers protected the underlying wood from photo-induced discolouration and there was little difference between them [69]. In contrast, Forsthuber and co-workers found that micronized titanium dioxide in an acrylic clear coat was slightly more effective than a triazine UVA at preventing the photo-induced discolouration of coated spruce panels exposed to UV light, and both were more effective than a micronized zinc oxide additive [70].

\subsection{Fungicides}

Surface fungi or moulds grow on most carbon-containing materials including wood, paint and clear coatings. Mould is a term used to describe a large and diverse group of fungi having well marked mycelium or spore mass [71]. Such fungi can perforate clear coatings on wood and grow within and beneath clear coatings, both of which can accelerate the failure of the coatings, as mentioned above $[7,25]$. Mould fungi disfigure the appearance of clear-coated wood, even if they don't destroy the film. Hence, there has been a significant research effort over many years to control the colonization of clear coatings by mould fungi. Most of this research has focused on the use of fungicides to control mould growth, but there has also been interest in how the chemical composition of the coating film and its intrinsic properties influence mould growth on coatings. The properties of the wood substrate beneath the coating also influence mould growth and we review this subject below.

Mould growth on paints and clear coatings can be surprisingly rapid particularly in humid tropical climates [72]. Coatings can contain readily available sources of carbon compounds, for example, plasticizers, emulsifiers, defoamers, thickeners and detergents, all of which can be metabolized by moulds and therefore encourage early colonization of coatings [72]. Some plasticizers favour mould growth more than others [72]. Benignus listed the plasticizers that have been found to be relatively resistant to fungal infection and others that are definitely not resistant to moulds [72]. He also mentioned that some oils can encourage mould growth in coatings, for example linseed, cottonseed, tall, fish, oiticica and soybean oils [72]. Oils that are less favoured by moulds include tung, pine, petroleum, most coal tar and some sulphonated oils [72]. Moulds also show a preference for some binders over others. For example, a study of the factors affecting the colonization of fungicidal coatings by moulds found that a phenolic tung oil coating was more resistant than an alkyd resin modified nitrocellulose [73]. This study concluded that binder type exerted a large influence on mould growth on fungicidal coatings. The incorporation of fungicides in coatings is an obvious route to controlling mould growth on painted and clear-coated wood, but many of the fungicides that are highly effective at restricting mould growth at painted surfaces such as mercuric compounds, pentachlorophenol (PCP) and its sodium salt and many metal-containing 
biocides are no longer available. Hansen listed the fungicides that could be used to control mould in solvent and water-borne coatings [71]. They included carbendazim, chlorothalonil, copper napthenate, 4, 5-Dichloro-2-n-octyl-isothiazolin-3-one, dichlorofluanid, folpet, iodo-2-propynylbutylcarbamate, 2-Octyl-3(2H)-ísothiazolone, tolyfluanid and various azole and zinc and quaternary ammonium compounds [71]. Even this restricted number of biocides may diminish in future according to Hansen [71]. Furthermore, the effectiveness of biocides in and beneath coating films diminishes with outdoor exposure due to volatilization, leaching and, in the case of organic fungicides, their degradation by UV radiation $[74,75]$. Hence, to reduce the growth of moulds on coatings, greater attention is being given to decreasing the hygroscopicity of coating films and controlling moulds in other ways. For example, Hofmann reported that faster drying and harder varnish films were less susceptible to colonization by moulds [76]. In contrast, Gobakken and Høibø reported that soft paint films were more resistant to colonization by mould fungi than harder films [77]. This discrepancy underlines the importance of obtaining a better understanding of how coating hardness and other surface properties including roughness and wettability influence the colonization of coatings by mould fungi. Such insights may allow the development of complementary approaches to controlling mould fungi that can be used in combination with fungicides to increase the performance of clear coatings on wood.

\section{Modification of Wood to Improve Clear-Coat Performance}

The properties of wood and its susceptibility to degradation by water, micro-organisms and light exert a major influence on the performance of clear finishes. Accordingly, the performance of clear coatings can be improved by altering wood properties particularly its dimensional and photostability and its resistance to microbial degradation. This section reviews the research that has been performed to increase the longevity of clear coatings by modifying the wood substrate. The most successful attempts to increase coating performance have tried to select a durable clear coating that complements the modified wood substrate, and we comment on this approach in our concluding remarks.

\subsection{Wood Properties}

The properties of wood exert a major influence on the performance of exterior wood finishes, which is why the longevity of clear coatings on wood vary significantly between wood species $[11,36]$. Irrespective of wood species there is a need to physically modify wood to ensure that coatings perform well. Such modifications include rounding sharp edges and filling large vessels to ensure that the coating is thick enough to minimize checking at edges and over vessels and resin canals [37]. Sanding of planed surfaces can improve the performance of finishes, and Miniutti commented on the need to develop a method of surfacing wood that removed projecting cell wall-areas where clear coatings tended to fail [22]. Minimizing the grain raising of wood may also be important because Butin suggested that raised fibres acted as conduits for the colonization of clear-coated wood samples by blue stain fungi [31]. Some studies have observed that clear coatings perform better on rougher sanded surfaces than on smoother ones [14], and there is certainly stronger evidence that semi-transparent stains perform better on rougher surfaces than smoother ones because more stain is absorbed by rough surfaces compared to smooth ones [78]. The different properties of earlywood and latewood at wood surfaces and grain direction also influences the performance of clear finishes [37]. All these effects point to the 
need to carefully select and prepare wood substrates to maximize the longevity of clear coatings on wood. Even if this is the case, the susceptibility of wood beneath clear coatings to photodegradation and the apparent ease with which water and staining fungi can access wood beneath coatings provide obstacles to the development of durable clear coatings that have yet to be completely surmounted. However, it is clear that modification of wood to increase its photostability, water repellency, dimensional stability and resistance to staining fungi can significantly improve the performance of clear coatings on wood. The performance of clear coatings on wood can also be improved by modifying the wood coating interface to improve coating adhesion and penetration although there has been less research on this topic than on wood pre-treatments.

\subsection{Dimensional Stabilization of Wood}

The swelling and shrinkage of wood when it gains or loses moisture (dimensional instability) causes checks to develop at wood surfaces, even when they are coated. Checking of wood imposes strains on clear coatings that cause them to crack. Hence, improving the dimensional instability of wood is an obvious route to improving the performance of clear coatings. The methods of dimensionally stabilizing wood that have been shown to improve the performance of clear coatings on wood include bulking the wood cell wall with polyethylene glycol, pre-treatment with water repellents, and various wood modification treatments including impregnation with resins and various esterification reactions, for example, acetylation.

\subsubsection{Polyethylene Glycol}

Polyethylene glycol (PEG) is a polyether compound that has widespread industrial and medicinal uses. Its most common use for wood protection is to preserve water-logged ships timbers, for example the timbers in the Vasa in Sweden and the Mary Rose in the UK. PEG achieves its protective effect by replacing water in wood cell walls, keeping the wood in a permanently swollen condition and preventing it from checking and distorting when the wood dries. PEG can be easily leached from wood, but leaching is restricted by coatings. The effects of PEG on the performance of clear coatings were examined by Stamm [79]. He pre-treated redwood samples with PEG and then finished them with a "two-can" polyurethane or a marine spar varnish. The coatings restricted the leaching of PEG from the redwood samples, but when the samples were oven dried the spar varnish developed blisters, whereas the polyurethane was blemish-free. Stamm went on to expose PEG-pre-treated and polyurethane-coated samples to the weather [79]. He found that there was no loss of gloss or failure of the two-part polyurethane coating on pre-treated redwood samples exposed to the weather for 18 months [79]. Subsequent experiments with a one-part polyurethane or a phenolic varnish were not as successful because material exuded through these finishes [79]. The same exudation did not occur through an alkyd varnish [79]. These results led Stamm to speculate that the two-part polyurethane performed better than other clear finishes applied to PEG-treated wood because it was chemically bonded to wood [79]. He also noted that the PEG restricted colour changes and photo-oxidation at wood surfaces [79]. Stamm's pioneering research led to further research on the ability of PEG to improve the performance of clear coatings on wood. For example, Kiguchi and co-workers found that pre-treatment of Douglas fir plywood with a $10 \%$ solution of PEG prevented failure of clear finishes when the coated composite 
was exposed outdoors for two years (Figure 8) [80]. In accord with the findings of Stamm and Kiguchi and co-workers [79,80], Podgorski and Roux also observed that a primer containing PEG improved the performance of a water-borne acrylic coating with a solids content of $\sim 40 \%$ [81]. Chang and co-workers pretreated the red heartwood of Taiwan cedar with 30\% PEG and found that the treatment was able to reduce discoloration of clear coated (polyurethane plus UVA) wood to the same extent as a solution of UVA and HALS [55]. However, they noted that the brightness of the heartwood beneath the clear coating was increased. They attributed this increase in brightness to photodegradation of PEG and the production of hydroperoxides, which bleached heartwood [55]. Ohkoshi observed that PEG-4000 did not restrict colour changes of four Japanese wood species exposed to UV radiation, but it reduced the rate of photodegradation of lignin [82]. However, PEG was degraded by light, and hence Ohkoshi suggested that this might limit its effectiveness in the long-term [82]. Hon and co-workers also used a PEG pre-treatment in an attempt to improve the performance of clear-coated wood [83]. Their research tested the ability of PEG alone, or in combination with a polymer containing a built-in UV absorber, to photostabilize southern pine [83]. The same polymer was also used in clear coats. Both the pre-treatment and coating were able to photostabilize wood, and Hon and co-workers concluded that the combination of the two systems "will make a potential and important contribution to photostabilization of wood and wood surfaces" [83].
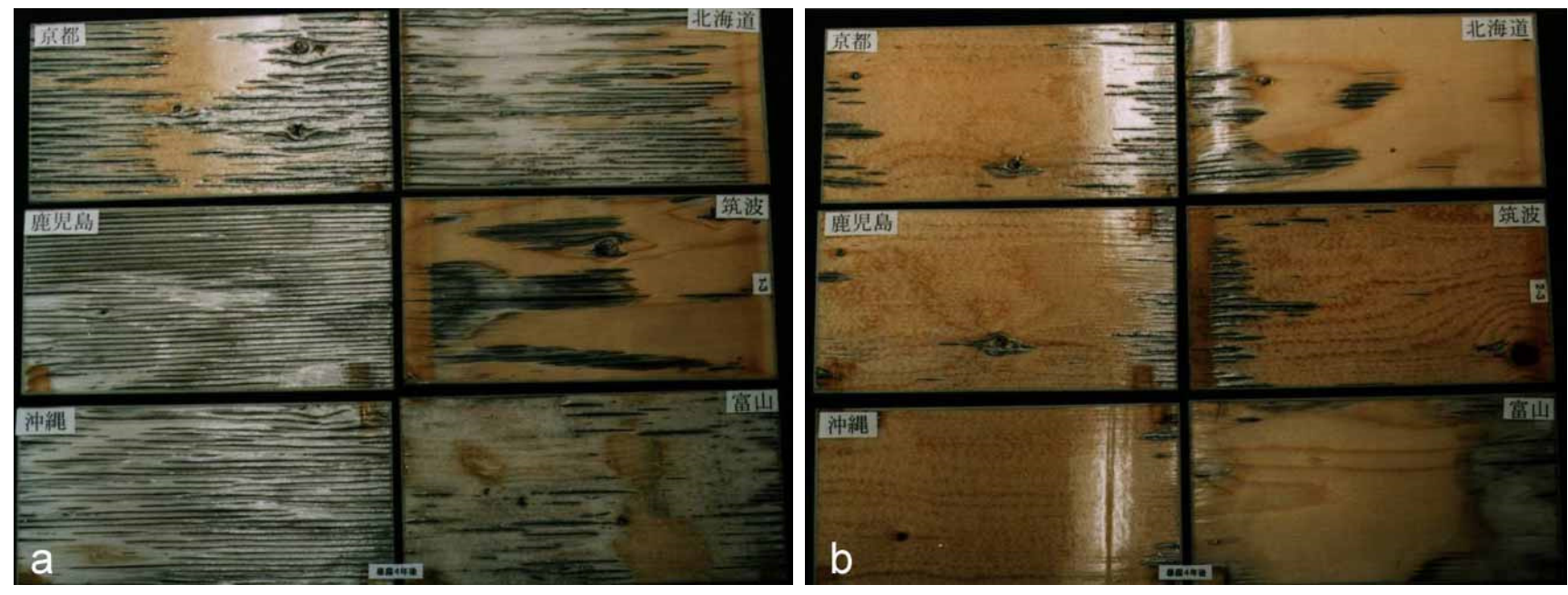

Figure 8. Effect of a polyethylene glycol (PEG) pre-treatment on the performance of a clear coating on Douglas fir plywood panels exposed outdoors for two years at six different sites in Japan: (a) Untreated clear-coated panels; (b) Clear-coated panels pre-treated with 10\% PEG.

\subsubsection{Water Repellents}

Water-repellents are solvent-based or aqueous treatments that can be used as a finish or as a pre-treatment beneath clear or opaque film-forming coatings. Water-repellents contain hydrophobes (wax and/or oil), a binder, fungicide and (optionally) pigments. Water repellents reduce the rate of water absorption by wood and provide increased dimensional stability. As a result they restrict the surface checking of wood. There are many studies demonstrating that water repellents improve the performance of opaque coating on wood [78,84], but there are fewer studies that have tested them in combination with clear coatings. Black and Mraz found that a water-repellent pre-treatment containing a UV absorber 
(dibenzoyl resorcinol) improved the exterior performance of polyurethane, silicone and acrylate clear coatings on redwood and western red cedar for the first two to three years of outdoor exposure, but the coatings degraded quite quickly thereafter [36]. Black and Mraz also tested the ability of chemical modification (resin treatment) and inorganic chemicals to improve the performance of clear coatings. Both of these approaches were more successful than the water repellent at improving the performance of clear coatings [36].

\subsubsection{Chemical Modification}

Wood can be chemically and physically modified to increase its dimensional stability. A large number of such treatments have been developed and the literature on the subject is vast (see text by Hill for a comprehensive treatise on the subject [85]). However, relatively few modification treatments find commercial application or have been tested to see if they improve the performance of clear coatings. The exceptions are acetylation, thermal modification and impregnation of wood with either phenol formaldehyde resin or dimethylol resins.

Tarkow and co-workers tested whether the performance of oil modified polyurethane or polyacrylate clear coatings on pine was improved by pre-treating the wood with phenol formaldehyde (PF) resin [86]. They also tested a polyurethane finish on PF-treated redwood. Two PF treatments were used: immersion or impregnation, and the treated and coated panels were exposed to accelerated weathering [86]. The PF pre-treatment improved the performance of the clear coatings, particularly the polyacrylate which was less sensitive to the effects of UV radiation [86]. The coatings performed better on wood that had been impregnated rather than immersed in resin [86]. Tarkow and co-workers concluded that the improvements in performance of the clear coatings could not be entirely explained by the ability of the PF resin to dimensionally stabilize wood, and they speculated that some of the improvement could be due to the PF resin acting as a massive UV absorber, thereby reducing degradation of wood beneath the clear coating [86]. Black and Mraz examined the ability of PF resin to improve the performance of clear coatings on redwood and western red cedar [36]. However, they applied the PF resin by brush rather than impregnating the wood with resin [36]. Not surprisingly, in light of Tarkow and co-workers' results [86], they found that the PF resin pre-treatment had limited ability to improve the performance of three different clear coatings (polyurethane, silicone and acrylate coatings) [36]. The ability of the brush-on PF resin pre-treatment to improve the performance of the clear coatings exposed to natural weathering was only slightly better than that of the water repellent pre-treatment mentioned above, but it was far less effective than an acid copper-chromate pre-treatment [86]. More recent research on the performance of clear coatings on PF resin treated wood has confirmed that PF resin pre-treatment is effective at improving the performance of water-borne acrylic and alkyd clear coatings, especially if the photostability of the coating is increased by doubling the level of UVA/HALS in the coating [34].

$\mathrm{PF}$ resin treatment of wood has been commercialized in Japan by Kyushu Mokuzai and the modification of wood with dimethylol resins has been commercialized in Europe. Modification of wood with the resin dimethylol dihydroxyethyleneurea (DMDHEU) is unable to photostabilize lignin, but it dimensionally stabilizes wood and provides some protection to wood from the deleterious effects of weathering [87]. When used as a pre-treatment it reduced the discolouration and cracking of semi-transparent varnishes on Scots pine panels exposed to natural weathering for 18 months [88]. Acetylation is another 
modification process that improves the dimensional stability of wood and it too has been commercialized in Europe. There have been a number of studies that have examined the performance of opaque coatings on acetylated wood. Most of these studies have shown that the performance of opaque coatings is better on acetylated wood than on unmodified wood. Fewer studies of the performance of clear coatings on acetylated wood have been conducted, but they have shown that clear coatings perform better on acetylated wood than on unmodified wood. For example, Beckers and co-workers observed that the reflectance of a UV stabilized acrylic clear coat on acetylated Scots pine was virtually unchanged after $1728 \mathrm{~h}$ of accelerated weathering [89]. They concluded that acetylation can prevent discolouration or failure of a fully transparent coating after severe artificial weathering. They went on to suggest that acetylated wood "gives new opportunities for finishing wood with clear unpigmented coatings since coating durability is strongly improved" [89]. Their comments may have been a little premature since a recent study found that a clear polyurethane varnish on acetylated rubberwood was starting to fail after 2 years outdoor exposure in India, even though the varnish was performing much better on acetylated than on unmodified rubberwood [19]. Wood that is heat treated is less hygroscopic, and more durable, and dimensionally stable than unmodified wood and such thermally modified wood is used commercially in above-ground applications, for example siding (cladding) and decking where it is often finished with opaque or semi-transparent coatings. Jämsä and co-workers concluded that thermal modification does not adversely affect the performance of coatings on wood and no alterations in coating protocols are required when finishing thermally modified wood [90]. However, the performance of coatings on heat treated wood may vary with wood species, For example, Feist and Sell found that semi-transparent and film-forming stains performed slightly better on thermally modified beech, but their performance was slightly worse on thermally modified spruce compared to their performance on unmodified spruce [91]. Thermally modified wood surfaces are less wettable than unmodified wood and, as a result, plasma modification was used to increase the wettability of thermally modified wood and to make it more compatible with coatings [81]. However, no effect of plasma treatment on the performance of coatings was observed when plasma pre-treated and coated heat treated wood was exposed to accelerated weathering [81]. Other wood modification systems that have been tested to see if they improve the performance of clear coatings on wood include esterification with the aromatic compounds benzoyl chloride or vinyl benzoate and the etherification modifications, cyanoethylation, benzylation and allylation. The latter two modifications improved the performance of clear coatings [92] as did modification of wood with the aromatic compounds benzoyl chloride and vinyl benzoate [19,34]. The effects of wood modification with these two aromatic compounds on the performance of clear coatings are examined in more detail below.

\subsection{Photostabilization of Wood}

Clear coatings transmit visible light and some are transparent to UV radiation. UV radiation degrades wood surfaces beneath clear coatings and the more energetic component of the visible spectrum (violet-blue) can also do the same, albeit at a reduced rate [93]. Photodegradation of wood beneath clear coatings leads to their failure by loss of adhesion (delamination and peeling), as mentioned above, and is a fundamental obstacle to improving the performance of clear coatings on wood [94]. This limitation was grasped by many of the early researchers that worked on formulating improved clear coatings for 
wood, including Estrada [3] and Ashton and co-workers [5,43]. Therefore, it is not surprising that considerable research has been performed since this time to develop photo-protective pre-treatments or primers to improve the performance of clear coatings on wood. These primers include simple brush-on pre-treatments including solvent-borne or aqueous solutions of reactive metal compounds (chromium in particular), and UVA/HALS, as well as more elaborate systems that involve grafting UV absorbers to wood.

\subsubsection{Reactive Metal Systems}

The only wood clear coating system that has matched the performance of opaque coatings, and therefore met market expectations, is a system that consisted of a durable silicone clear coating applied to wood that had been treated with chromium VI compounds. The silicone coating was UV transparent and performed well even on untreated wood until it failed by loss of adhesion to the photodegraded, underlying wood substrate. Chromium VI pre-treatment of wood is remarkably effective at photostabilizing lignin, the photolabile component of wood, and it also improves the water-repellency of the surface and makes it less susceptible to colonization by micro-organisms. When a chromium VI pre-treatment was combined with a silicone coating the longevity of the finish was increased dramatically, in excess of 15 years in fully exposed condition [95], to as much as 30 years in-service (Figure 9). This dramatic increase in coating performance stimulated research to understand the chemistry of the photostabilization of wood by chromium VI and to develop alternative metal pre-treatments. Chromium VI pre-treatment of wood was commercialized in Japan where it was used to improve the longevity of clear acrylic urethane finishes on wooden doors [96]. However, the toxicity of chromium VI and the fact that it imparts a green/brown colouration to wood, discouraged further commercial development of chromium VI pre-treatments for clear coatings. Attempts to reproduce the same effects on clear coating performance with other transition metal compounds, including $\mathrm{Cr}$ III, Ti, V, Mn, Fe, Co, Ni, Cu, Zn, Mo, and even Os and Pt have been unsuccessful. However, combinations of sodium molybdate and either ferric or copper compounds were almost as successful as $\mathrm{Cr}$ VI at improving the performance of a silicone clear coating exposed to artificial or accelerated weathering [36]. For example, a silicone clear coating on wood pre-treated with sodium molybdate and iron was still in very good condition after 6 years of outdoor exposure [36]. Unfortunately, the treated wood was black which no doubt discouraged further use of this pre-treatment. The same problem has prevented more widespread use of manganese compounds which are able to photostabilize lignin, although not to the same extent as Cr VI [97]. Some colourless titanium and zirconium compounds are able to improve the performance of clear coatings on wood, but this positive effect is not related to their ability to photostabilize lignin, but to their effect on the adhesion of the coating to the wood substrate [97]. Therefore they are examined below in the section on modification of the wood coating interface. 

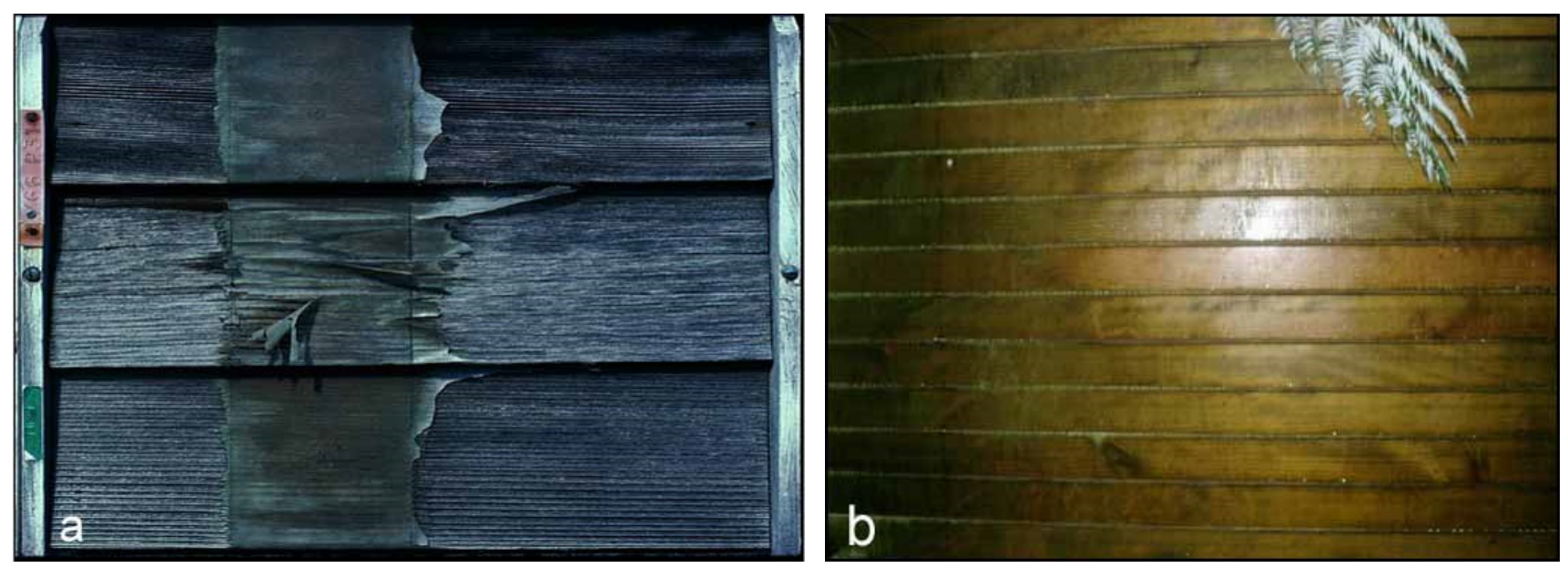

Figure 9. Effect of chromium VI pre-treatment on the performance of clear finishes on wood: (a) Silicone clear coating adhering to pre-treated wood exposed to the weather for $\sim 15$ years (the finishes to the right and left of the silicone finish have been completely degraded and lost, photo c/o Sam Williams US Forest Products Laboratory; (b) Clear coating performing well on Cr VI pretreated wood after 28 years of outdoor exposure.

\subsubsection{Photostabilizers}

Many of the UV absorbers and hindered amine light stabilizers that have been added to clear coatings to improve their performance have also been used as wood-pre-treatments. Some studies have combined UVA/HALS pre-treatments with clear coatings that also contained UV absorbers and HALS. For example, Chang and co-workers found that pre-treatment of wood surfaces with a benzotriazole UV absorber was able to restrict photo-induced colour changes of Taiwan cedar heartwood that had been finished with a clear coating containing a UVA [55]. Pre-treatment of wood surfaces with a HALS restricted colour changes of Taiwan cedar heartwood exposed to fluorescent UV light, and a synergistic effect was observed between a HALS and a benzotriazole UV absorber on heartwood colour stability [55]. George and co-workers suggested that impregnation of wood surfaces with HALS prior to the application of a clear coat containing a UVA could be a useful strategy for protecting wood from photodegradation and enhancing the performance of clear coatings used outdoors [98]. Rogez and co-workers described the synergistic effects of combinations of UV absorbers and HALS on the performance of clear coatings on wood, and the progress made to develop more effective combinations of UV absorbers and HALS for the photoprotection of wood and clear finishes $[17,99,100]$. They described a state-of-the-art system for photostabilizing wood beneath clear coatings. This system consisted of a clear coating containing a "red-shifted" triazine UV absorber (1\%-1.5\%) and a HALS (0.5\%) applied to wood that had been pretreated with a HALS (2\%) specifically designed to trap the radicals formed as a result of the degradation of lignin by light. This system was able to successfully prevent the degradation of clear-coated radiata pine panels exposed to the weather in Switzerland for 18 months [17]. Exposed wood panels lost very little of their original colour and no coating defects were present after outdoor exposure [17]. Forsthuber and Grüll further examined the effectiveness of the photoprotective system described by Schaller and Rogez [17,59], but they extended the concept by using inorganic photostabilizers as well as UVA/HALS combinations in clear coatings. They concluded that "careful selection of light 
stabilizers, such as $\mathrm{TiO}_{2}$ or UVA in combination with HALS in the topcoat, as well as a lignin stabilizer in an aqueous primer can significantly improve the colour retention of wood" (exposed to UV radiation) [59]. We have also observed that pre-treatment of wood with a primer containing UVA/HALS in combination with a UV resistant clear coating can significantly improve the performance of clear coatings (Figure 10).
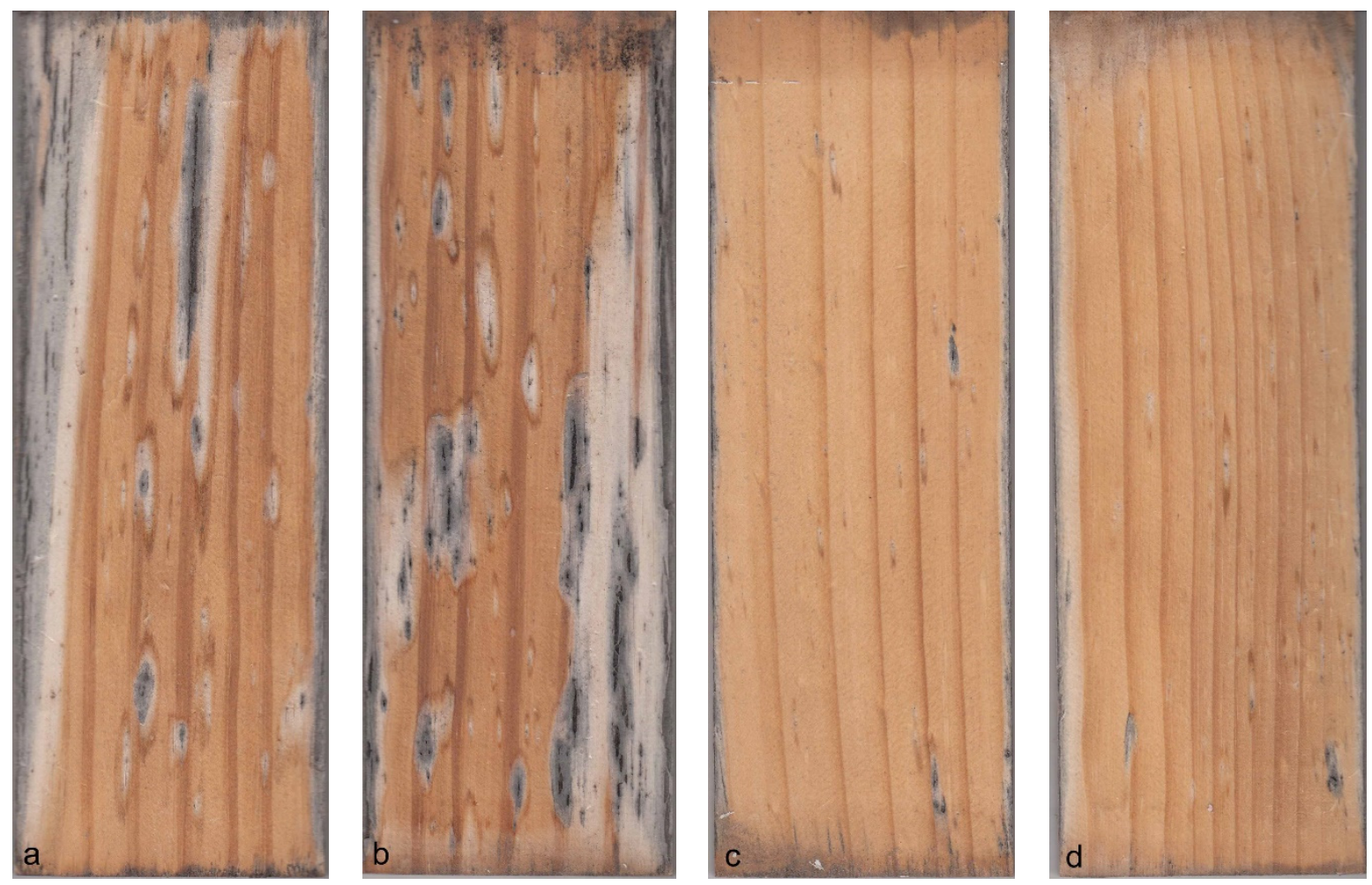

Figure 10. Effect of pre-treating radiata pine with a combination of a UV absorber and a hindered amine light stabilizer (HALS) on the performance of a durable acrylic coating: (a,b) Untreated controls exposed to the weather for 28 months in Canberra, Australia. Note darkening of wood beneath the coating and failure of the coating; (c) Panel pre-treated with a UVA and low molecular weight HALS; (d) Panel pre-treated with a UVA and an oligomeric HALS (panels are $23 \mathrm{~cm} \times 8 \mathrm{~cm}$ in size, length $\times$ width)

\subsubsection{Grafting of UV Absorbers to Wood}

The permanence and effectiveness of UV absorbers at preventing the photodegradation of polymers can be improved by chemically bonding the UV absorber to the polymer, and this approach has also been used to protect wood from photodegradation. The majority of published research in this area has employed either benzophenone or triazine UV absorbers containing an epoxy group. These UV absorbers can be permanently bonded to wood at high temperatures in the presence of an amine catalyst [12,23,101]. Grafting of epoxy-functionalized UV absorbers to wood protected wood from photodegradation and also improved the performance of clear coatings on modified wood surfaces (Figure 11). Another route to grafting UV absorbers to wood is to employ UV absorbers containing an isocyanate group. Grelier and co-workers reported that the photo-yellowing of wood could be restricted by grafting an isocyanate-modified benzotriazole UV absorber to wood, and pretreating the surface with radical scavengers such as polyethylene glycol or HALS [102]. Grelier and co-workers also grafted a 
polystyrene-maleic anhydride copolymer containing polyethylene glycol chains and a benzotriazole UV absorber (both with acyl azide functionality) to wood [103]. This grafting treatment improved the colour stability of wood exposed to UV light and the adhesion of clear varnishes on grafted wood exposed to artificial accelerated weathering, but it was less effective at preventing the discoloration of finished wood [103].
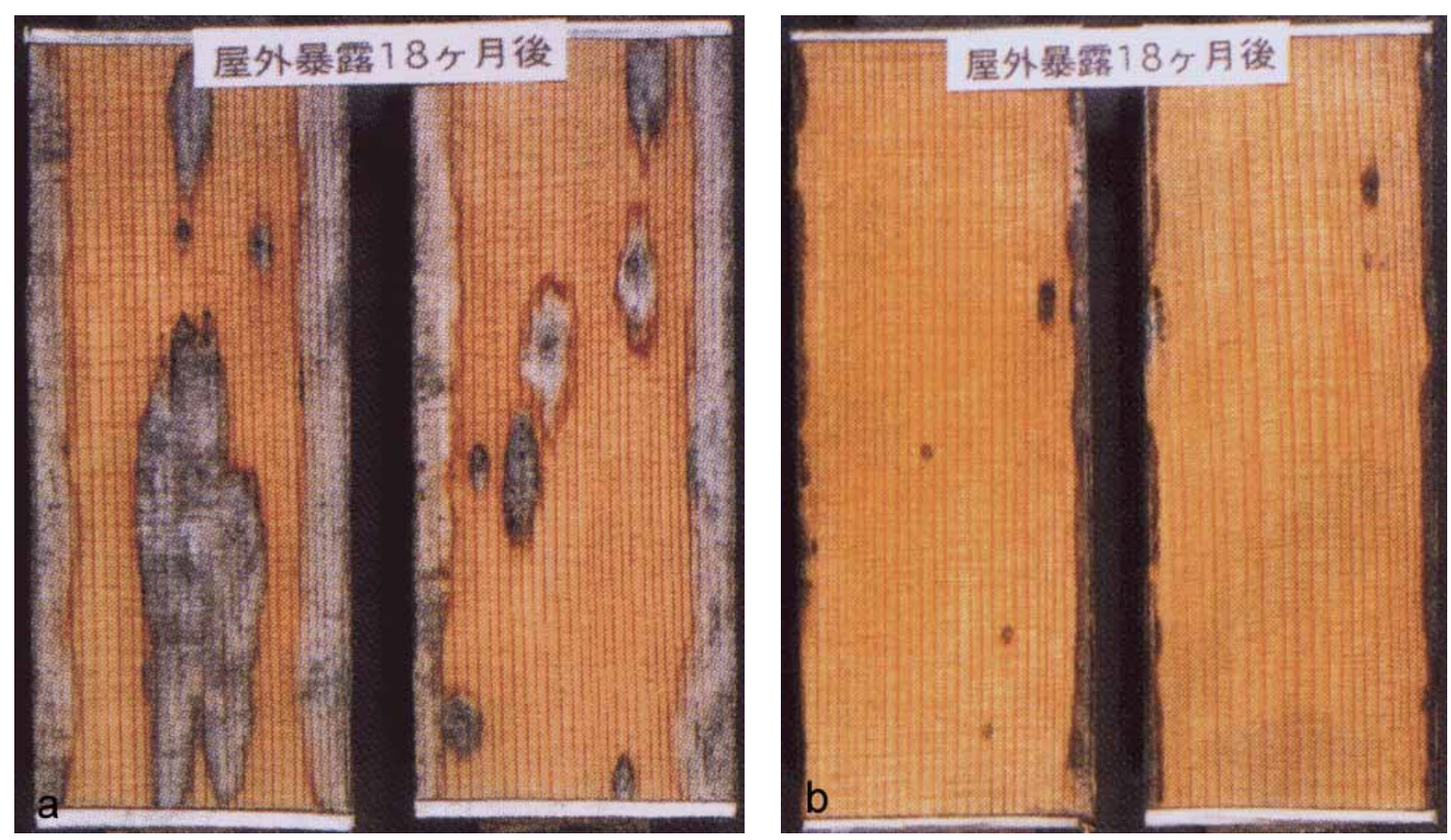

Figure 11. Effects of grafting the epoxy-functionalized UV absorber, 2-hydroxy-4(2,3epoxypropoxy)-benzophenone on the performance of an acrylic silicone clear coating on sugi wood: (a) Unmodified wood; (b) Wood treated to a weight gain of 5.6\%. Unmodified and treated and coated panels were exposed to the weather for 18 months in Tsukuba, Japan.

An alternative to grafting UV absorbers to wood is to esterify wood with aromatic compounds, which absorb UV radiation. This approach involves esterifying wood with benzoyl chloride or vinyl benzoate [104-106]. Both approaches photostabilize lignin, although they are not as effective as chromium VI, and they also increase the longevity of clear coatings [19,34]. However, wood esterified by benzoyl chloride or vinyl benzoate and then clear-coated becomes white with prolonged exposure to the weather, which is undesirable in a pre-treatment designed to improve the performance of clear finishes [34].

\subsection{Pre-Treatment of Wood with Fungicides}

Moulds and staining fungi can accelerate the failure of coatings on wood, and for this reason fungicides are often added to coatings to improve their performance, as mentioned above. Alternatively, or additionally, wood can be pre-treated with fungicides to prevent surface fungi from damaging coatings applied to wood. For example, Uiterwaal and Blom mentioned that most woods are susceptible to colonization by blue stain fungi, and that the fungi can contribute to the failure of coatings [30]. They pointed out the need to pre-treat wood with a fungicide and also add one to the coating to prevent the deterioration of coatings by blue stain fungi. Similarly, Sell mentioned the need to pre-treat wood with 
a fungicide to prevent blue-staining of coated joinery, but he cautioned that "a priming coat impregnation below a non-poisonous surface coating does not permanently protect against blue-stain fungi" [24]. Therefore he recommended that coated joinery should be protected against blue stain fungi by constructive measures that prevent water ingress into the joinery. Water ingress into joinery and also its colonization by blue-stain often occurs via end-grain, emphasizing the importance of sealing end-grain as way of reducing the microbial deterioration of coatings on wood [107,108]. Sell also stressed the need to develop fungicides that stay fixed in the wood coating system and do not affect adhesion of the coating to the underlying wood [24]. Baker and co-workers evaluated the ability of three fungicidal pre-treatments (PCP, phenyl mercury succinate and the azole, Preventol) to prevent blue staining of Scots pine finished with a clear alkyd varnish [109]. Treated and finished samples were subjected to artificial weathering (and then incubated in pure cultures of staining fungi), or simply exposed to 6 months of natural weathering. The azole preservative was slightly more effective at preventing blue stain than phenyl mercury succinate and both were better than PCP. This order of comparative effectiveness was the same irrespective of whether natural or artificial weathering was used to evaluate the test chemicals. Bravery and Miller noted that superficial treatment of wood with preservatives such as chromated copper arsenate (CCA), PCP and tributyl tin oxide (TBTO) failed to provide long term protection to painted joinery against blue-stain [32]. The limited ability of PCP and TBTO to control blue stain was thought to be due, in part, to tolerance of some strains of the ubiquitous surface staining fungus $A$. pullulans to these chemicals and possibly detoxification of TBTO [32]. Bravery and Miller suggested that control of blue stain requires the use of fungicides that are specifically active against staining fungi [32]. Nevertheless, chemicals such as PCP and copper napthenate appear to be more effective at controlling fungal staining of wood when added to water-repellents [110]. Milano found that pre-treatment of pine and eucalypt sapwood with CCA or a water-dispersible PCP preservative improved the performance of a polyurethane varnish when treated and coated L-joints were exposed outdoors in Brazil for 10 months [10]. CCA was more effective with pine than with the eucalypt and it was better than PCP at reducing film failure (cracking and peeling of the coating) [10]. Kiguchi and co-workers found that the fungicide didecyldimethylammonium chloride, when used as a pre-treatment, was ineffective at improving the performance of clear coatings on Douglas fir plywood exposed to natural weathering for 2 years at six sites in Japan [80]. Recently, Stirling and Morris tested a range of organic preservatives as pre-treatments designed to improve the performance of a semi-transparent stain on pine and spruce [18]. They found that fungicidal pre-treatment improved the performance of the finish, and the combination of fungicide and photostabilizers was even more effective. Nevertheless, the gains in performance even with the most effective pre-treatments were modest and they indicated that coated samples exposed at the challenging Mississippi test site would need refinishing after 3 years outdoor exposure [18].

\section{Modifying the Wood-Coating Interface}

Clear coatings can fail at the wood coating interface due to loss of adhesion or photodegradation and failure of wood immediately below the wood-coating interface. The latter can be reduced by photostabilizing the wood, but the same effect might be achieved by increasing the penetration of the coating beyond the depth at which significant photodegradation of wood occurs. Evidence for such an effect is limited, but in their extensive tests of clear coating performance Ashton, Harris and co-workers 
observed that low viscosity phenolic varnishes were superior to other formulations possibly because lower molecular weight materials were able to penetrate and reinforce the top layer of wood $[5,43]$. Such reinforcement was also reported by Miniutti during his microscopic observations of a transparent silicone coating on wood subjected to prolonged UV irradiation [22]. He noted that the silicone coating maintained its original position on wood by means of resin fingers that penetrated into the wood substrate [22]. In addition to increasing coating penetration, strengthening wood at the coating interface and chemically coupling the coating to the wood might also improve coating performance. These routes to improving the performance of clear coatings remain largely unexplored, but some steps in this direction have been taken.

Plasma treatments can improve the wettability of wood surfaces and the adhesion of lacquer to wood $[81,111]$. They can also increase the surface permeability of wood and the penetration of coatings into wood $[112,113]$. Therefore we hypothesized that plasma treatment would improve the performance of clear coatings on wood. We found that plasma pre-treatment improved the performance of an oil-borne polyurethane clear coating on black spruce exposed to artificial accelerated weathering (Figure 12), but it had no such effect on the performance of a water-borne polyurethane clear coating [113].
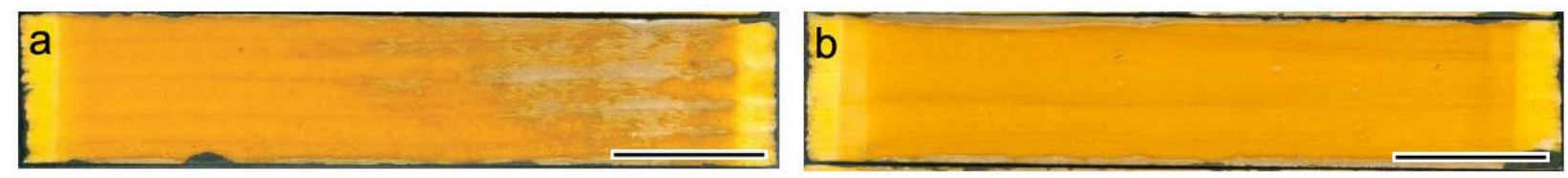

Figure 12. Effect of plasma treatment for $3 \mathrm{~min}$ on the performance on an oil-borne polyurethane coating on black spruce exposed to $2000 \mathrm{~h}$ of artificial accelerated weathering: (a) Untreated control; (b) Plasma treated. Scale bars $=15 \mathrm{~mm}$.

Strengthening the wood coating interface emerged as a possible route to improving clear coating performance during research to find transition metal compounds that could photostabilize wood and improve clear coating performance in the same way as chromium VI [97]. A range of different titanium and zirconium compounds were tested, some of which are used as coupling agents in polymers. Some of these compounds were able to strengthen wood, and the treated wood maintained its mechanical integrity during exterior exposure, even though the chemicals were unable to photostabilize lignin. Some of the compounds were able to improve the performance of an alkyd clear coating on western red cedar exposed to natural weathering (Figure 13).

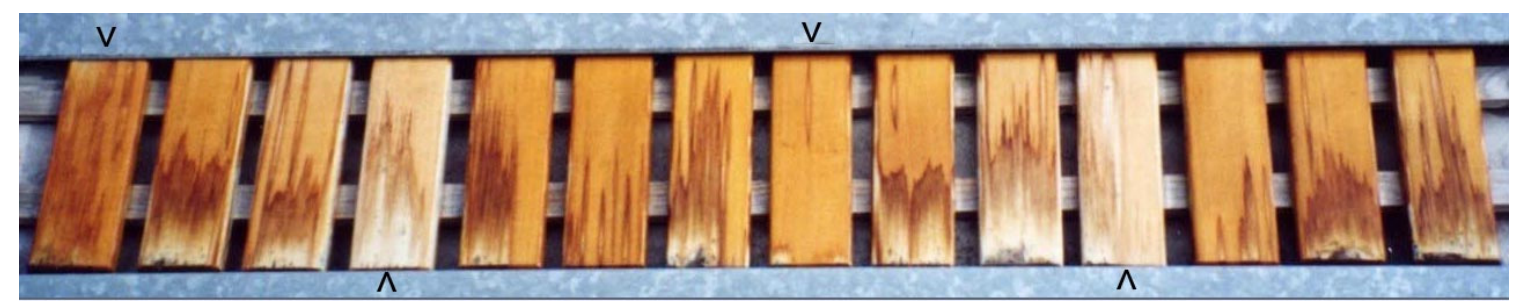

Figure 13. Appearance of an alkyd clear coating on western red cedar panels pre-treated with reactive titanium or zirconium compounds and exposed to the weather for 22 months in Australia. Note the positive effect of one of the compounds on the performance of the coating (arrowed top). Untreated controls are arrowed bottom (photo provided by Karl Schmalzl, formerly of CSIRO Division Forestry and Forest Products, Melbourne, Australia). 
Titanium and zirconium compounds also improved the performance of opaque coatings suggesting that their beneficial effects on clear coating performance were not related to their ability to photostabilize the wood, but to modification of the wood coating interface. Subsequent unpublished research has shown that the same compounds when used to treat wood can improve the adhesion of thermosetting glues suggesting that they improved clear coating performance by improving bond strength of the coating to wood. Further research is required to fully explore this hypothesis.

\section{Concluding Remarks}

The research to develop durable clear coatings for wood has failed, as there are no clear coatings on the market that match the performance of opaque coatings. However, there have been some serious and determined attempts to develop such coatings and these studies reveal that the durability of clear coatings can be extended far beyond the 2 years that is the benchmark for most commercial products. For example, Ashton and co-workers research with phenolic varnishes developed products that remained in good condition for nearly 5 years [5]. Important attributes of these coating were their ability to restrict water and water vapour from the underlying wood. Ashton also noted that the performance of phenolic varnishes varied with wood species and was better on white pine than on western red cedar [5]. He acknowledged that transmission of UV light limited the performance of clear finishes on wood, but his research did not combine durable phenolic varnishes with wood pre-treatments capable of significantly improving wood's photostability, and dimensional stability [5]. However, such treatments may have been able to extend the life-time of his best coatings beyond five years. Clear coating systems with life-times in excess of 5 years were developed by Black and Mraz [36]. Their research has attracted much attention, particularly their finding that chromium VI significantly improved clear coating durability because of its remarkable ability to photostabilize lignin. However, it is also important to note that their work was carried out with a stable substrate (edge grain redwood or western red cedar) and a durable silicone coating that was resistant to the effects of UV radiation and adhered well to wood. All these elements combined to create a durable clear coating system with a lifetime in excess of 15 years. The remarkable durability of the chromic acid silicone-clear coating system has overshadowed their findings that some iron and copper pre-treatments were also able to extend the lifetime of the silicone clear coating from two to six years. Subsequent research on improving the performance of clear coatings have all taken note of the need to photostabilize wood prior to the application of a clear coating and the most serious attempts have combined such pre-treatments with clear coatings that have been modified with additives to improve their durability. Most notable in this regard is the more recent research of Rogez and co-workers who used a lignin stabilizing wood pre-treatment and a clear coating containing state-of-the-art UV stabilizers $[17,99,100]$. Their research did not attempt to dimensionally stabilize the wood substrate or modify the system in other ways that could have further enhanced coating durability. We attempted to modify the wood substrate to increase dimensional stability and UV resistance, and then applied an acrylic clear coating to the modified wood that contained double the normal level of UV stabilizers [34]. The best performance was obtained on wood that had been esterified with benzoyl chloride, which is able to photostabilize lignin and dimensionally stabilize wood [104-106]. However, photo-bleaching of wood modified with benzoyl chloride occurred beneath clear finishes and such an effect also occurs with some other treatments that esterify wood, which makes then unsuitable 
as pre-treatments for clear coatings designed to maintain the natural appearance of wood [34]. The development of more durable clear coatings for wood requires the use of pre-treatments that are able to dimensionally and photostabilize wood, change or maintain its colour and also restrict microbial colonization of the wood coating interface. It is unlikely that such a treatment would be as effective as chromic acid at photostabilizing lignin and hence it would need to be combined with a highly photostable, impermeable, finish, possibly a flexible and durable silicone or acrylic containing additives able to restrict the transmission of UV and violet/blue light through the coating. Further measures would be required to make the coating resistant to bacterial and fungal colonization. The different elements of the defensive architecture within such a system would need to be compatible with each other and work together to prevent energetic radiation, water and micro-organisms from reaching the wood beneath the coating. Such a "systems approach" may represent the best route to the development of a new generation of more durable clear coatings. This approach is successful in other fields, for example the multilayered defensive architecture used to protect digital systems, which is analogous to the defensive system employed by medieval castles [114]. Both systems evolved over time and were frequently tested allowing them to become much better. Testing allowing the evolution and "hardening" of protective systems is essential. In the case of durable clear coatings designed to last a long time such testing requires a sustained commitment to $R \& D$ and the development of partnerships between organizations with structural stability (universities and some government laboratories) and coating and chemical companies. Such partnerships and the knowledge already amassed on the durability of clear coatings (reviewed above) could put the goal of a durable clear coating within the reach of the next generation of coating and wood scientists willing to confront this daunting challenge.

\section{Acknowledgments}

We thank Ecobuild (SP Trätek) and Canada's National Science and Engineering Research Council for recent financial support and Roger Heady, Hua Chen and Frank Brink of the Centre for Advanced Microscopy at The Australian National University (ANU) for technical assistance. PDE thanks Karl Schmalzl for his helpful comments; the Department of Applied Mathematics at The ANU for a Visiting Fellowship and Viance, Tolko, and FPInnovations for their support of his BC Leadership Chair at the University of British Columbia.

\section{Author Contributions}

\section{Philip D. Evans ${ }^{1,2, *}$, Jonathan G. Haase ${ }^{1}$, A. Shakri, B.M. Seman ${ }^{3}$ and Makoto Kiguchi ${ }^{4}$}

Philip D. Evans conceived and wrote this review, which incorporates original findings on the performance of clear finishes provided by Jonathan G. Haase, A. Shakri, B.M. Seman, and Makoto Kiguchi. All authors reviewed and approved the final version of the manuscript prior to publication.

\section{Conflicts of Interest}

The authors declare no conflict of interest. 


\section{References}

1. Finishes for Exterior Timber; Timber Research and Development Association: High Wycombe, UK, 1984; p. 8.

2. Sarvis, J.C. Exterior Clear Finishes; Western Pine Association Research Laboratory: Portland, OR, USA, 1953.

3. Estrada, N. Exterior durability of catalyzed clear coatings on redwood. J. Paint Technol. 1967, 39, $655-662$.

4. Fessel, F. Results of several years' weathering tests on surface-treated woods in exterior use in buildings. Holzzentralblatt 1966, 92, 257-261.

5. Ashton, H.E. Clear finishes for exterior wood. Field exposure tests. J. Paint Technol. 1967, 39, 212-224.

6. Resistencia a la Intemperie de Madera Revestida con Pinturas y Barnices; Notas Tecnicas: Santiago, Chile, 1967. (In Spanish)

7. Dickinson, D.J. Disfigurement of decorative timbers by blue stain fungi. Int. Pest Control 1972, $14,21-25$.

8. Borgin, K.; Corbett, K. A comparison of the effect of weathering of paints, varnishes and water repellents as coating systems for wood. S. Afr. For. J. 1973, 84, 10-15.

9. Macedo, D.R. Durability of exterior natural wood finishes in Brazil. In Proceedings of the International Research Group on Wood Preservation Meeting, Guaruja, Brazil, 12-17 May 1985; IRG Secretariat: Stockholm, Sweden, 1985; p. 8.

10. Milano, S. Performance of different treatments and finishes on wood out of ground contactPreliminary results. In Proceedings of the International Research Group on Wood Preservation Meeting, Ronneby Brunn, Sweden, 18 May-1 June 1984; IRG Secretariat: Stockholm, Sweden, 1984; p. 18.

11. Williams, R.S.; Feist, W.C. Performance of finishes on wood modified with chromium nitrate versus chromic acid. For. Prod. J. 1988, 38, 32-35.

12. Kiguchi, M.; Evans, P.D.; Ekstedt, J.; Williams, R.S.; Kataoka, Y. Improvement of the durability of clear coatings by grafting of UV-absorbers on to wood. Surf. Coat. Int. Part B Coat. Trans. 2001, 84, 263-270.

13. Kiguchi, M. Market for exterior wood products and exterior wood finishing in Japan. In High-Performance Utilization of Wood for Outdoor Uses; Imamura, Y., Ed.; Press-Net: Kyoto, Japan, 2001; pp. 33-43.

14. Morris, P.; McFarling, S.; Groves, K. Field Performance of Commercial Natural Finishes; Forintek Canada Corp.: Vancouver, BC, Canada, 2004; p. 48.

15. Morris, P.I.; McFarling, S. Enhancing the performance of transparent coatings by UV protective pre-treatments. In Proceedings of the International Research Group on Wood Protection Meeting, Tromsø, Norway, 18-22 June 2006; IRG Secretariat: Stockholm, Sweden, 2006; p. 11.

16. Petrič, M.; Kričej, B.; Pavlič, M.; Rapp, A. Natural weathering of coated oil heat treated wood. In Proceedings of the International Research Group on Wood Protection Meeting, Jackson Lake, Wyoming, WY, USA, 20-24 May 2007; p. 12. IRG Secretariat: Stockholm, Sweden 2007. 
17. Schaller, C.; Rogez, D. New approaches in wood coating stabilization. J. Coat. Technol. 2007, 4, 401-409.

18. Stirling, R.; Morris, P.I. Improved coating performance on wood treated with carbon-based preservatives and an ultraviolet/visible light protective precoat. For. Prod. J. 2013, 63, 95-100.

19. Pandey, K.K; Srinivas, K. Study of UV resistance and natural weathering of coatings on chemically modified wood. In Proceedings of the International Research Group on Wood Protection Meeting, Stockholm, Sweden, 16-20 June 2013; p. 14. IRG Secretariat: Stockholm, Sweden, 2013.

20. Grüll, G.; Tscherne, F.; Spitaler, I.; Forsthuber, B. Comparison of wood coating durability in natural weathering and artificial weathering using fluorescent UV-lamps and water. Eur. J. Wood Prod. 2014, 72, 367-376.

21. Hunt, J.K.; Lansing, W.D. Coating composition films. Physical properties and durability. Ind. Eng. Chem. 1935, 27, 26-29.

22. Miniutti, V.P. Microscopic Observations of Ultraviolet Irradiated and Weathered Softwood Surfaces and Clear Coatings; United States Department of Agriculture, Forest Service: Madison, WI, USA, 1967; p. 33.

23. Williams, R.S. Effect of grafted UV stabilizers on wood surface erosion and clear coating performance. J. Appl. Polym. Sci. 1983, 28, 2093-2103.

24. Sell, J. Investigations on the infestation of untreated and surface treated wood by blue stain fungi. Holz Roh Werkstoff 1968, 26, 215-222.

25. Sharpe, P.R.; Dickinson, D.J. Blue stain in service on wood surface coatings. Part 2. The ability of Aureobasidium pullulans to penetrate wood surface coatings. In Proceedings of the International Research Group on Wood Preservation Meeting, Harrogate, UK, 10-15 May 1992.

26. Miniutti, V.P. Microscale changes in cell structure at softwood surfaces during weathering. For. Prod. J. 1964, 14, 571-576.

27. Macleod, I.T.; Scully, A.D.; Ghiggino, K.P.; Ritchie, P.J.A.; Paravagna, O.M.; Leary, B. Photodegradation at the wood-clearcoat interface. Wood Sci. Technol. 1995, 29, 183-189.

28. Shakri, A. Weathering of Kempas and its Effects on the Adhesion and Performance of Surface Finishes. Ph.D. Thesis, The Australian National University, Canberra, Australia, 1995.

29. Singh, A.P.; Dawson, B.S.W. The mechanism of failure of clear coated wooden boards as revealed by microscopy. Int. Assoc. Wood Anat. J. 2003, 24, 1-11.

30. Uiterwaal, D.J.D.; Blom, C.W. The role of coatings in timber preservation. In Proceedings of the Record Annual Convention British Wood Preservers Association, Cambridge, UK, 2-5 July 1973.

31. Butin, H. Investigations on the formation of blue-stain on lacquered wood surfaces. Holz Roh Werkstoff 1961, 19, 337-340.

32. Bravery, A.F.; Miller, E.R. The role of pre-treatment in the finishing of exterior softwood. In Proceedings of the Record Annual Convention British Wood Preservers Association, Cambridge, UK, 24-27 May 1980.

33. Browne, F.L. Natural Wood Finishes for Exteriors of Houses; United States Department of Agriculture, Forest Service: Madison, WI, USA, 1951; p. 9.

34. Vollmer, S.; Evans, P.D. Performance of clear coatings on modified wood exposed to the weather for 2 years in Australia. Int. Wood Prod. J. 2013, 4, 177-182. 
35. Schuh, A.E.; Theuerer, H.C. Organic finishes - Effect of film thickness on physical properties and exposure behavior. Ind. Eng. Chem. 1937, 29, 182-189.

36. Black, J.M.; Mraz, E.A. Inorganic Surface Treatments for Weather Resistant Natural Finishes; United States Department of Agriculture, Forest Service: Madison, WI, USA, 1974; p. 40.

37. Van Loon, J. The interaction between paint and substrate. J. Oil Col. Chem. Assoc. 1966, 49, 844-867.

38. Cassens, D.L.; Feist, W.C. Finishing Wood Exteriors. Selection, Application, and Maintenance; United States Department of Agriculture, Forest Service: Madison, WI, USA, 1986; p. 56.

39. Ashton, H.E. Flexibility and its retention in clear coatings exposed to weathering. J. Coat. Technol. 1979, 51, 41-52.

40. Schmid, E.V. Exterior wood-coatings and the glass-transition temperature. Polym. Paint Col. J. 1988, 178, 460-468.

41. Podgorski, L.; Merlin, A.; Deglise, X. Analysis of the natural and artificial weathering of a wood coating by measurement of the glass transition temperature. Holzforschung 1996, 50, 282-287.

42. Ashton, H.E. Predicting durability of clear finishes for wood from basic properties. J. Coat. Technol. 1980, 52, 63-71.

43. Harris, J.; Ashton, H.E.; O'Doherty, G.A. Exterior Exposure of Clear Organic Coatings on Wood; National Research Council Canada, Division Building Research: Ottawa, ON, Canada, 1964; p. 52.

44. Preston, A.F.; Chittenden, C.M. Accelerated tests of weather resistant natural finishes for Pinus radiata. J. Coat. Technol. 1978, 50, 59-61.

45. Kiefer, J.R., Jr. Ultraviolet light absorbers in clear coatings for wood. J. Paint Technol. 1967, 39, 736-751.

46. Gantz, G.M.; Sumner, W.G. Stable ultraviolet light absorbers. Textile Res. J. 1957, 27, $244-251$.

47. Van Allan, J.; Tinker, J.F. Derivatives of benzoylresorcinol. J. Org. Chem. 1954, 19, 1243-1251.

48. Estrada, N. Exposure characteristics of clear finishes for exterior wood surfaces. For. Prod. J. 1958, 8, 66-72.

49. Estrada, N. Exterior finishes for wood-Some of the problems involved. For. Prod. J. 1959, 9, A28-A31.

50. Rothstein, E.C. Compatibility and reactivity of UV absorbers in clear coatings. J. Paint Technol. 1967, 39, 621-628.

51. Ashton, H.E. Exterior exposure study of stains and clear finishes. Can. Paint Finish. 1974, 48, 13-16.

52. Chang, S.-T.; Chou, P.-L. Photodiscoloration inhibition of wood coated with UV-curable acrylic clear coatings and its elucidation. Polym. Deg. Stab. 2000, 69, 355-360.

53. Chou, P.-L.; Chang, H.-T.; Yeh, T.-F.; Chang, S.-T. Characterizing the conservation effect of clear coatings on photodegradation of wood. Bioresour. Technol. 2008, 99, 1073-1079.

54. Shenoy, M.A.; Marathe, Y.D. Studies on synergistic effect of UV absorbers and hindered amine light stabilizers. Pigment Resin Technol. 2007, 36, 83-89.

55. Chang, S.-T.; Wang, S.-Y.; Su, Y.-C. Retention of red color in Taiwania (Taiwania cryptomeriodes Hay.) heartwood. Holzforschung 1998, 52, 13-17. 
56. Aloui, F.; Ahajji, A.; Irmouli, Y.; George, B.; Charrier, B.; Merlin, A. Photostabilisation of the "wood-clearcoatings" systems with UV absorbers: Correlation with their effect on the glass transition temperature. J. Phys. Conf. Ser. 2006, 40, 118-123.

57. Hayoz, P.; Peter, W.; Rogez, D. A new innovative stabilization method for the protection of natural wood. Prog. Organic Coat. 2003, 48, 297-309.

58. Pereira, J.; Eusébio, M. Waterborne acrylic varnishes durability on wood surfaces for exterior exposure. Prog. Org. Coat. 2006, 56, 59-67.

59. Forsthuber, B.; Grüll, G. The effects of HALS in the prevention of photodegradation of acrylic clear topcoats and wooden surfaces. Polym. Deg. Stab. 2010, 95, 746-755.

60. Nikolic, M.; Lawther, J.M.; Sanadi, A.R. Use of nanofillers in wood coatings: A scientific review. J. Coat. Technol. Res. 2015, 12, 445-461.

61. Esposito Corcione, C.; Frigione, M. UV-cured polymer-boehmite nanocomposite as protective coating for wood elements. Prog. Org. Coat. 2012, 74, 781-787.

62. Boxall, J.; Laidlaw, R.A.; Hayes, G.F.; Miller, E.R. The performance of extender-modified clear finishes on exterior timber. J. Oil Col. Chem. Assoc. 1984, 67, 227-233.

63. Aloui, F.; Ahajji, A.; Irmouli, Y.; George, B.; Charrier, B.; Merlin, A. Inorganic UV absorbers for the photostabilisation of wood-clearcoating systems: Comparison with organic UV absorbers. Appl. Surf. Sci. 2007, 253, 3737-3745.

64. Allen, N.S.; Edge, M.; Ortega, A.; Liauw, C.M.; Stratton, J.; McIntyre, R.B. Behaviour of nanoparticle (ultrafine) titanium dioxide pigments and stabilisers on the photooxidative stability of water based acrylic and isocyanate based acrylic coatings. Polym. Deg. Stab. 2002 78, 467-478.

65. Weichelt, F.; Emmler, R.; Flyunt, R.; Beyer, E.; Buchmeiser, M.R.; Beyer, M. ZnO-based UV nanocomposites for wood coatings in outdoor applications. Macromol. Mat. Eng. 2010, 295, 130-136.

66. Cristea, M.V.; Riedl, B. Enhancing the performance of exterior waterborne coatings for wood by inorganic nanosized UV absorbers. Prog. Org. Coat. 2010, 69, 432-441.

67. Auclair, N.; Riedl, B.; Blanchard, V.; Blanchet, P. Improvement of photoprotection of wood coatings by using inorganic nanoparticles as ultraviolet absorbers. For. Prod. J. 2011, 61, 20-27.

68. Schaller, C.; Rogez, D.; Braig, A. Organic vs. inorganic light stabilizers for waterborne clear coats: A fair comparison. J. Coat. Technol. Res. 2012, 9, 433-441.

69. Ozgenc, O.; Hiziroglu, S.; Yidiz, U. Weathering properties of wood species treated with different coating applications. Bioresources 2012, 7, 4875-4888.

70. Forsthuber, B.; Schaller, C.; Grüll, G. Evaluation of the photo stabilising efficiency of clear coatings comprising organic UV absorbers and mineral UV screeners on wood surfaces. Wood Sci. Technol. 2013, 47, 281-298.

71. Hansen, K. Molds and moldicide formulations for exterior paints and coatings. In Development of Commercial Wood Preservatives, Efficacy, Environmental and Health Issues; Schultz, T.P., Militz, H., Freeman, M.H., Goodell, B., Nicholas, D.D., Eds.; ACS: Washington, DC, USA, 2008; pp. 198-213.

72. Benignus, P.G. Mildew problems of interest to paint, varnish and lacquer manufacturers. Paint Oil Chem. Rev. 1947, 110, 10-30, 34.

73. Leonard, J.M.; Pitman, A.L. Tropical performance of fungicidal coatings. A statistical analysis. Ind. Eng. Chem. 1951, 43, 2338-2341. 
74. Lee, D.-H.; Tsunoda, K.; Takahashi, M. Photostability of organoiodine wood preservatives I. Progressive degradation and loss in fungal inhibition rate through photoirradiation. Mokuzai Gakkaishi 1991, 37, 76-81.

75. Sandermann, W.; Carsten, R.; Krasting, W.; Pieper, J. Studies in the field of wood protection chemistry. Holzforschung 1958, 10, 57-66.

76. Hofmann, W.F. A review of work done on mildew prevention. Am. Paint J. 1938, 22, 22-24, 58,60 .

77. Gobakken, L.R.; Høibø, O.A. Aesthetic service life of coated and uncoated wooden cladding - Influencing factors and modelling. In Proceedings of the International Research Group on Wood Protection Meeting, Queenstown, New Zealand, 8-12 May 2011.

78. Feist, W.C. Weathering performance of painted wood pretreated with water-repellent preservatives. For. Prod. J. 1990, 40, 21-26.

79. Stamm, A.J. Modification of wood for improved finishing. Offic. Dig. J. Paint Technol. Eng. 1965, 37, 707-719.

80. Kiguchi, M.; Kataoka, Y.; Doi, S.; Mori, M.; Hasegawa, M.; Morita, S.; Kinjo, M.; Kadekaru, Y.; Imamura, Y. Improvement of weather resistance of film-forming type clear finishes by pre-treatment with PEG and influence of exposure test sites. Mokuzai Hozon 1997, 22, 10-17.

81. Podgorski, L.; Roux, M. Wood modification to improve the durability of coatings. Sur. Coat. Int. 1999, 82, 590-596.

82. Ohkoshi, M. FTIR-PAS study of light-induced changes in the surface of acetylated or polyethylene glycol-impregnated wood. J. Wood Sci. 2002, 48, 394-401.

83. Hon, D.N.-S.; Chang, S.-T.; Feist, W.C. Protection of wood surfaces against photooxidation. J. Appl. Polym. Sci. 1985, 30, 1429-1448.

84. Feist, W.C. Weathering of wood and its control by water-repellent preservatives. In Wood Protection Techniques and the Use of Treated Wood in Construction; Hamel, M.P., Ed.; Forest Products Research Society: Madison, WI, USA, 1988; pp. 82-88.

85. Hill, C.A.S. Wood Modification. Chemical, Thermal and other Processes; John Wiley \& Sons: Chichester, UK, 2006.

86. Tarkow, H.; Southerland, C.F.; Seborg, R.M. Surface Characteristics of Wood as they Affect Durability of Finishes. Part I. Surface Stabilization; United States Department of Agriculture, Forest Service: Madison, WI, USA, 1966; p. 22.

87. Xie, Y.; Krause, A.; Mai, C.; Militz, H.; Richter, K.; Urban, K.; Evans, P.D. Weathering of wood modified with the $N$-methylol compound 1,3-dimethylol-4,5-dihydroxyethyleneurea. Polym. Deg. Stab. 2005, 89, 189-199.

88. Xie, Y.; Krause, A.; Militz, H.; Mai, C. Weathering of uncoated and coated wood treated with methylated 1,3-dimethylol-4,5-dihydroxyethyleneurea (mDMDHEU). Holz Roh Werkstoff 2008, 66, 455-464.

89. Beckers, E.P.J.; de Meijer, M.; Militz, H. Performance of finishes on wood that is chemically modified by acetylation. J. Coat. Technol. 1998, 70, 59-67.

90. Jämsä, S.; Ahola, P.; Viitaniemi, P. Long-term natural weathering of coated ThermoWood. Pigment Resin Technol. 2000, 29, 68-74. 
91. Feist, W.C.; Sell, J. Weathering behavior of dimensionally stabilized wood treated by heating under pressure of nitrogen gas. Wood Fiber Sci. 1987, 19, 183-195.

92. Kiguchi, M. Chemical modification of wood surfaces by etherification. II. Weathering ability of hotmelted wood surfaces and manufacture of self hot-melt bonded particleboard. Mokuzai Gakkaishi 1990, 36, 867-875.

93. Kataoka, Y.; Kiguchi, M.; Williams, R.S.; Evans, P.D. Violet light causes photodegradation of wood beyond the zone affected by ultraviolet light. Holzforschung 2007, 61, 23-27.

94. Derbyshire, H.; Miller, E.R. The photodegradation of wood during solar irradiation. Part 1. Effects on the structural integrity of thin wood strips. Holz Roh Werkstoff 1981, 39, 341-350.

95. Williams, R.S.; Feist, W.C. Wood modified by inorganic salts: Mechanism and properties. I. Weathering rate, water repellency, and dimensional stability of wood modified with chromium (III) nitrate versus chromic acid. Wood Fiber Sci. 1985, 17, 184-198.

96. Ohtani, K. Chromium trioxide enhances the durability of wooden doors. Chrom. Rev. 1987, 8, 4-7.

97. Schmalzl, K.J.; Evans, P.D. Wood surface protection with some titanium, zirconium and manganese compounds. Polym. Deg. Stab. 2003, 82, 409-419.

98. George, B.; Suttie, E.; Merlin, A.; Deglise, X. Photodegradation and photostabilisation of wood-The state of the art. Polym. Deg. Stab. 2005, 88, 268-274.

99. Schaller, C.; Rogez, D. Defended from the sun. Eur. Coat. J. 2006, 12, 22-27.

100. Rogez, D. Color stabilization of wood and durability improvement of wood coatings: A new UV light-protection concept for indoor and outdoor applications. Paint Coat. Ind. 2002, 18, 56-65.

101. Kiguchi, M.; Evans, P.D. Photostabilisation of wood surfaces using a grafted benzophenone UV absorber. Polym. Deg. Stab. 1998, 61, 33-45.

102. Grelier, S.; Castellan, A.; Desrousseaux, S.; Nourmamode, A.; Podgorski, L. Attempt to protect wood colour against UV/visible light by using antioxidants bearing isocyanate groups and grafted to the materials with microwave. Holzforschung 1997, 51, 511-518.

103. Grelier, S.; Castellan, A.; Podgorski, L. Use of low molecular weight modified polystyrene to prevent photodegradation of clear softwoods for outdoor use. Polym. Deg. Stab. 2007, 92, $1520-1527$.

104. Evans, P.D.; Owens, N.L.; Schmid, S.; Webster, R.D. Weathering and photostability of benzoylated wood. Polym. Deg. Stab. 2002, 76, 291-303.

105. Pandey, K.K.; Chandrashekar, N. Photostability of wood surfaces esterified by benzoyl chloride. J. Appl. Polym. Sci. 2006, 99, 2367-2374.

106. Jebrane, M.; Sebe, G.; Cullis, I.; Evans, P.D. Photostabilization of wood using aromatic vinyl esters. Polym. Deg. Stab. 2009, 94, 151-157.

107. Carey, J. Assessing the performance of preservative treatments for wooden joinery. Holz Roh Werkstoff 1982, 40, 269-274.

108. Miller, E.R.; Boxall, J. The effectiveness of end-grain sealers in improving paint performance on softwood joinery. Holz Roh Werkstoff 1984, 42, 27-34.

109. Baker, J.M.; Miller, E.R.; Morgan, J.W.W.; Savory, J.G. Research in wood protection at the Princes Risborough Laboratory 1973 and 1974. Record Annual Convention British Wood Preservers Association: Cambridge, UK, 24-27 June 1975. 
110. Feist, W.C. The Role of Water Repellents and Chemicals in Controlling Mildew on Wood Exposed Outdoors; United States Department of Agriculture, Forest Service: Madison, WI, USA, 1984; p. 16.

111. Rehn, P.; Wolkenhauer, A.; Bente, M.; Förster, S.; Viöl, W. Wood surface modification in dielectric barrier discharges at atmospheric pressure. Surf. Coat. Technol. 2003, 174, 515-518.

112. Haase, J.G.H. Plasma Treatments and Coating Performance. Master's Thesis, University of British Columbia, Vancouver, BC, Canada, 2011.

113. Haase, J.; Evans, P.D. Plasma modification of wood surfaces to improve the performance of clear coatings. In Proceedings of the 5th European Conference on Wood Modification, Riga, Latvia, 20-21 September 2010.

114. Heusser, M. What Medieval Castles Can Teach You about Web Security. Available online: http://blog.smartbear.com/design/what-medieval-castles-can-teach-you-about-web-security/ (accessed on 5 August 2015).

(C) 2015 by the authors; licensee MDPI, Basel, Switzerland. This article is an open access article distributed under the terms and conditions of the Creative Commons Attribution license (http://creativecommons.org/licenses/by/4.0/). 